\title{
The Extracellular Matrix and Biocompatible Materials in Glioblastoma Treatment
}

\author{
Andrei Belousov ${ }^{1}$, Sergei Titov ${ }^{1,2}$, Nikita Shved ${ }^{1,3}$, Mikhail Garbuz ${ }^{1}$, Grigorii Malykin ${ }^{1,3}$, \\ Valeriia Gulaia ${ }^{1}$, Alexander Kagansky ${ }^{1}$ and Vadim Kumeiko ${ }^{1,2,3 *}$ \\ ${ }^{1}$ School of Biomedicine, Far Eastern Federal University, Vladivostok, Russia, ${ }^{2}$ School of Natural Sciences, Far Eastern \\ Federal University, Vladivostok, Russia, ${ }^{3}$ A.V. Zhirmunsky National Scientific Center of Marine Biology, Far Eastern Branch of \\ Russian Academy of Sciences, Vladivostok, Russia
}

\section{OPEN ACCESS}

Edited by:

Nihal Engin Vrana

Sparta Medical, France

Reviewed by:

Chandra Kothapalli,

Cleveland State University,

United States

Jianxun Ding,

Changchun Institute of Applied

Chemistry (Chinese Academy of

Sciences), China

*Correspondence:

Vadim Kumeiko

vkumeiko@yandex.ru

Specialty section: This article was submitted to

Biomaterials,

a section of the journal

Frontiers in Bioengineering and

Biotechnology

Received: 10 September 2019

Accepted: 30 October 2019

Published: 19 November 2019

Citation:

Belousov A, Titov S, Shved N

Garbuz M, Malykin G, Gulaia V, Kagansky A and Kumeiko V (2019)

The Extracellular Matrix and

Biocompatible Materials in

Glioblastoma Treatment.

Front. Bioeng. Biotechnol. 7:341.

doi: 10.3389/fbioe.2019.00341
During cancer genesis, the extracellular matrix (ECM) in the human brain undergoes important transformations, starting to resemble embryonic brain cell milieu with a much denser structure. However, the stiffness of the tumor ECM does not preclude cancer cells from migration. The importance of the ECM role in normal brain tissue as well as in tumor homeostasis has engaged much effort in trials to implement ECM as a target and an instrument in the treatment of brain cancers. This review provides a detailed analysis of both experimental and applied approaches in combined therapy for gliomas in adults. In general, matrix materials for glioma treatment should have properties facilitating the simplest delivery into the body. Hence, to deliver an artificial implant directly into the operation cavity it should be packed into a gel form, while for bloodstream injections matrix needs to be in the form of polymer micelles, nanoparticles, etc. Furthermore, the delivered material should mimic biomechanical properties of the native tissue, support vital functions, and slow down or stop the proliferation of surrounding cells for a prolonged period. The authors propose a two-step approach aimed, on the one hand, at elimination of remaining cancer cells and on the other hand, at restoring normal brain tissue. Thereby, the first bioartificial matrix to be applied should have relatively low elastic modulus should be loaded with anticancer drugs, while the second material with a higher elastic modulus for neurite outgrowth support should contain specific factors stimulating neuroregeneration.

Keywords: glioblastoma, biocompatible material, extracellular matrix, cancer treatment, drug delivery, CNS reconstruction, neuroregeneration

\section{INTRODUCTION}

Malignant neoplasms are among the most important global health problems. There are many different types of malignant neoplasms, which are divided depending on the location of the tumor, the stage of development and other characteristics. However, among the most dangerous group of tumors are malignant neoplasms of the brain due to their significant impact on the patient's life in physical, psychological and neurological aspects ( $\mathrm{Ng}$ et al., 2019), which can lead to permanent disability (Kunert et al., 2011).

Among all brain tumors, glioblastoma multiforme (GBM) is the most common one in adults as well as the most aggressive. GBM has a poor prognosis, since the tumor is considered incurable and the median patient survival is 15 months. In addition, there are no preventive measures that could 
preclude the development of the disease or improve its outcome (Bastiancich et al., 2018; Pinel et al., 2019). Pediatric gliomas (019 years old) deserve special attention, although their incidence is relatively low, around $3 \%$ of all brain and CNS tumors (Ostrom et al., 2014). The development of pediatric gliomas has several hallmark differences, for example, they carry distinct marker mutation histone $\mathrm{H} 3 \mathrm{~K} 27 \mathrm{M}$ substitution and more frequently exhibit p53 alterations, while PTEN deletion and EGFR amplification are more rare compared to primary adult GBM (Suri et al., 2009), however more detailed studies on the differences between pediatric and adult gliomas have already been cited in review articles (Fangusaro, 2012; Sturm et al., 2017). Current manuscript focuses only on the treatment of adult gliomas.

Standard treatment of a malignant neoplasm of the brain involves visualization of the tumor, its surgical resection without causing neurological damage, and is accompanied by therapeutic treatment (Yamahara et al., 2010).

After the diagnosis of glioblastoma and its surgical removal, the patient undergoes subsequent treatment with radiotherapy and concomitant chemotherapy with various cytotoxic drugs for around 6 weeks. However, during the development of a tumor its cells aggressively migrate and grow into surrounding structures of the brain, which makes it impossible to completely remove the internal neoplasm surgically leading to almost $100 \%$ relapse rate. In addition, long-term post-operative recovery may delay the subsequent stages of treatment, which contributes to the proliferation of residual tumor cells, leading to recurrence of GBM within 2 years after the initial diagnosis in most patients (Bastiancich et al., 2016b; Pinel et al., 2019).

Summarizing all the facts mentioned above, the traditional approach to treating cancer focuses only on tumor cells, ignoring their non-cellular environment, specifically, their extracellular matrix (ECM). However, it has been proven that the key role in the development and progression of a tumor is not played by tumor cells themselves, but by the ECM and the tumor stem cell niche it forms (Kim et al., 2005; Mikhailova et al., 2018). Understanding this role is crucial for predicting the fate and behavior of the remaining cancer cells and the dynamics of recovery (Mercier, 2016; Reinhard et al., 2016).

ECM undergoes changes as long as life endures. Specific molecular architecture of ECM provides for the differentiation and migration of neural progenitor cells in early development. Upon transition to adulthood, a partial change in the molecular pattern and matrix composition occurs, which supports lower migration ability, low proliferative activity, but retains axon

\footnotetext{
Abbreviations: $\mathrm{BBB}$, blood-brain barrier; BDNF, brain-derived neurotrophic factor; CNS, central nervous system; CPT, Camptothecin; CSC, cancer stem cell; CSPG, chondroitin sulfate proteoglycan; DMA, dimethacrylate; ECM, extracellular matrix; EGFR, epidermal growth factor receptor; FDA, Food and Drug Administration; GAG, glycosaminoglycan; GBM, glioblastoma multiforme; GelMA, gelatin methacryloyl; GFP, green fluorescence protein; HA, hyaluronic acid; HSPG, heparan sulfate proteoglycan; LNC, lipid nanocapsules; MMP, matrix metalloproteinase; NSC, neural stem cell; PEG, polyethylene glycol; PLA, polylactic acid; PLGA, poly(lactic-co-glycolic acid); PNN, perineuronal net; PTX, Paclitaxel; SPIO, superparamagnetic iron oxide; TGP, Thermo-Reversible Gelation Polymer; TMZ, temozolomide; VEGF, vascular endothelial growth factor.
}

guidance. During cancer genesis, the adhesive properties of the matrix are weakened and the matrix is remodeled, which leads to its juvenile composition, but its rigidity increases significantly, both in comparison with the juvenile and adult state. The use of biocompatible matrix materials, both natural and synthetic, on the one hand creates a new microenvironment in cells, becoming able to deliver anticancer therapeutic agents (drugs, cells, genetic engineering constructs), and, on the other hand, due to the "cell-matrix" interaction, can contribute to the remodeling of native ECM in the lesion, ensuring the progress of a "healthy" microenvironment, and the resumption of control of cell proliferation. The described transformations of the natural matrix and the necessary changes in the composition of biocompatible matrix materials during the treatment of gliomas are presented in this paper.

The use of various synthetic or natural materials that mimic normal ECM and create a microenvironment for cells in the resection cavity after removing a brain tumor can significantly improve the prognosis, which leads to a great interest in research in this area, and various types of matrix materials and methods are being developed.

In this article, we overview (i) the structure of normal ECM, which is a model for artificial matrix materials to imitate (ii) changes of ECM molecular profile during carcinogenesis to better understand the effect of tumors on the extracellular space, (iii) the possibility of influencing the tumor itself through various matrices by its molecular environment, and (iv) the latest trends in choosing matrix materials for creating implants.

\section{THE EXTRACELLULAR MATRIX OF THE HUMAN BRAIN}

Human brain is a very complex structure, in comparison to other organs, in terms of its tissue architecture at the first place. Brain neural tissue functions as a dynamic networkbeneficial synaptic connections need to be maintained, and other reconstructed to match changing input stimuli.

Cell-cell interactions in the brain, similarly to other tissues, are based on direct contacts via cadherins and signaling receptors, as well as cell-matrix interactions with the ECM (Senkov et al., 2014). Various molecules compose the neural ECM in the brain (Table 1).

While the role of neural elements in functioning of the brain is universally recognized and extensively studied, the importance of neural ECM is less widely reviewed.

The ECM consists of hundreds of different molecules that interact in complex and highly organized ways (Figure 1A). The major classes of macromolecules in the ECM are the structural glycoproteins (such as collagens, elastins, fibronectins, and laminins), proteoglycans (e.g., heparan sulfate), and glycosaminoglycans (GAGs), such as hyaluronan. Components of the ECM interact with each other; and interactions between the matrix and cells are of a vital importance to the functioning of the tissue. Previously it was considered that the ECM plays mostly structural role in tissues, but lately it has become clear that ECM is involved in determining cell fate, cell 
TABLE 1 | The key components of the brain ECM (from Novak and Kaye, 2000, modified).

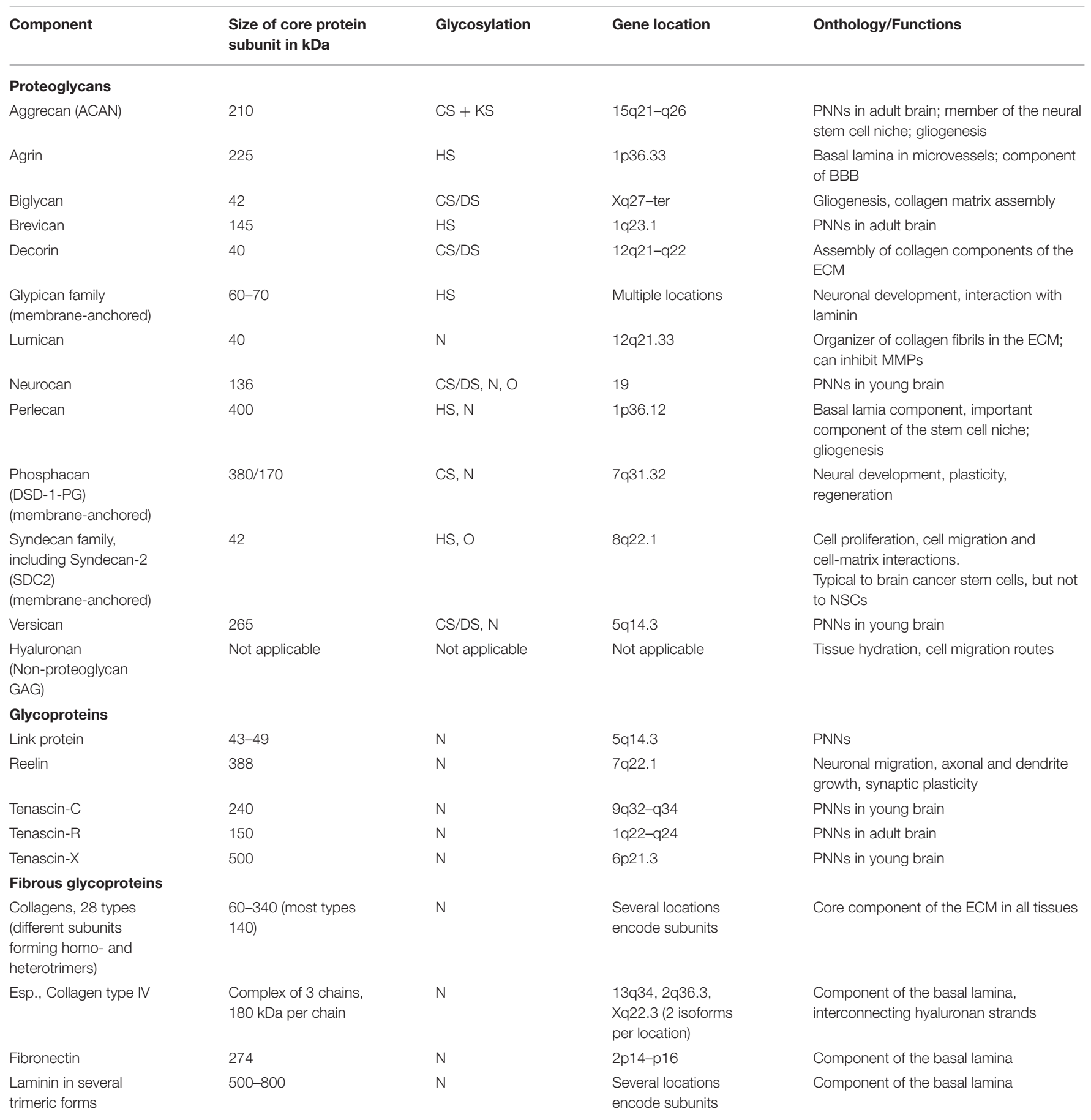

BBB, blood brain barrier; CS, chondroitin sulfate; CSC, cancer stem cell; DS, dermatan sulfate; HS, heparan sulfate; $K S$, keratan sulfate; MMP, matrix metalloproteinases; $N$, N-linked glycosylation; NSC, neural stem cell; PNN, perineuronal net; O, O-linked glycosylation; ND, not determined.

migration, cell maturation and differentiation, cell survival, tissue homeostasis, and tumor cell invasion. Specific surface receptors are expressed by cells, which mediate these responses (Plopper, 2015). Sometimes it can be hard to determine the precise role of different matrix components, as mutant forms of these components cause early embryonic death in experimental animals (Novak and Kaye, 2000).
Different tissues have unique and specialized ECM composition and structure, which enables ECM to carry interacting with these extracellular matrix components, including receptors which are not presented in tissue-specific roles, including structural support, macromolecular filtration, cell migration, and other functions (Hay, 1993; Mecham, 2012). Brain ECM contains relatively small amounts of fibrous 


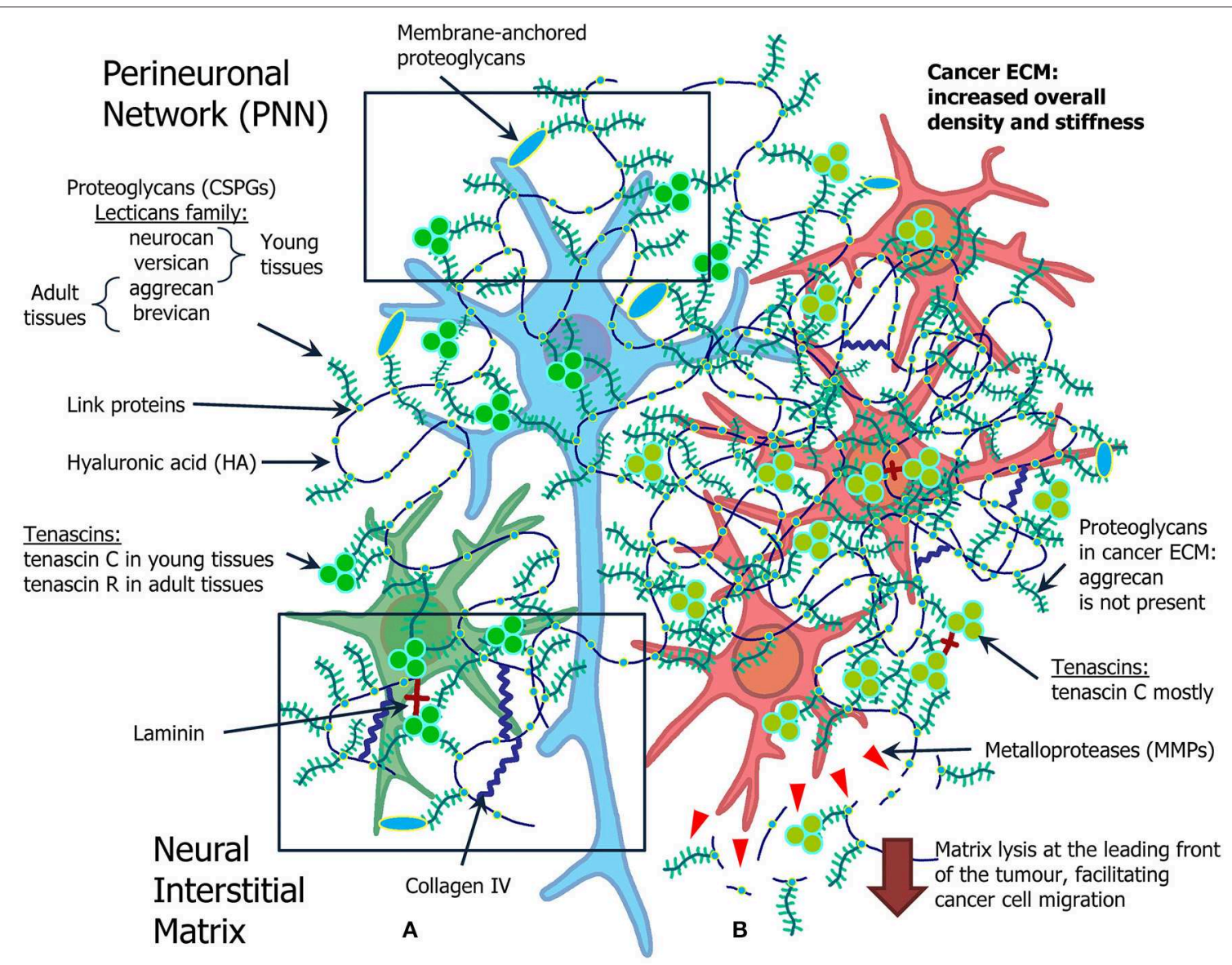

FIGURE 1 | Overview of the ECM in the normal brain and in brain tumors. (A) Normal ECM profile in the adult CNS (left): normal neuron (blue) and glial cell (green) are surrounded by proteoglycans (neurocan, versican, aggrecan, brevican), hyaluronic acid, tenascins (tenascin C and tenascin R), laminin, and collagen IV. (B) Cancer microenvironment formed by the atypical ECM, its role in cancer stem cell niche organization and cell migration (right). Glioma cells (red) grow in ECM with increased density and stiffness, as a lot of components of normal ECM are overexpressed in glioma milieu. The most pronounced difference is expression of MMPs, selection for tenascin C mostly common for young tissue, and absence of aggrecan.

proteins like collagens or fibronectin but high amounts of glycosaminoglycans, either bound to proteins, thus forming proteoglycans, or unbound in the form of hyaluronan (Novak and Kaye, 2000). Although, collagens, especially collagen IV, serve as an important organizing molecule in both young and adult brain ECM. Withal, there is a family of so-called small leucine-rich proteoglycans, which includes several members, such as decorin and biglycan (family I) and lumican (family II), which take a crucial role in collagen fibrils assembly (Yu et al., 2017).

One of the very basic components of brain ECM, both adult and young, is hyaluronan, or hyaluronic acid (HA). It is a type of a non-proteoglycan GAG found in all human tissues and body fluids, and is especially abundant in embryonic tissues. $\mathrm{HA}$ is also synthesized during tissue regeneration in wounds, as well as during pathological processes in which cell migration plays a major role, such as cancer genesis, and especially tumor cell invasion (Bouterfa et al., 1997). Also, it is shown that concentration of HA is higher in brain tumors, such as gliomas, than in normal brain tissues (Delpech et al., 1993), this aspect will be discussed further.

Although, many key components of the adult brain ECM are also widely present in various other tissue types, brain ECM is especially GAG-rich, its structure is somewhat more amorphous (e.g., compared to that of connective tissues and basal laminae of epithelia), and different components of ECM tend to form a unique type of basic structure, a perineuronal net (PNN) (Mouw et al., 2014).

This core assembly of the adult brain extracellular matrix, which is found mainly in pericellular spaces of neurons, is believed to be the hyaluronan-lectican-tenascin- $\mathrm{R}$ complex. Aggrecan, brevican, neurocan, versican are chondroitin sulfate proteoglycans (CSPGs), members of lecticans family. Core proteins of these proteoglycans include a hyaluronanbinding domain and a C-type lectin domains, through which lecticans interact with carbohydrate and protein ligands in the extracellular matrix and act as linkers of these ECM molecules. In the adult brain, lecticans are thought to interact with hyaluronan 
and tenascin-R to form a ternary complex of PNNs (Yamaguchi, 2000). Besides these roles typical to ECM, and a probable involvement in preserving neuronal health, PNNs are thought to be critical for maintaining synaptic plasticity (Lau et al., 2013).

\section{THE EXTRACELLULAR MATRIX OF BRAIN TUMORS, CHANGES IN THE COMPOSITION OF THE MATRIX DURING ONCOGENESIS}

Brain tumors, especially gliomas, trigger significant alterations of the ECM in brain tissues (Figure 1B).

Such changes include altered synthesis of the components by the tumor cells, extensive degradation of the ECM at the invasive front of the tumor, as well as an elevated level of synthesis of ECM components by normal tissues in the vicinity of the invading tumor.

Normal adult brain cells tend to display significant changes in the levels of ECM components produced in the presence of tumor cells. It was shown that normal cells have the ability to produce extracellular matrix components, such as laminin, collagen type IV and fibronectin, when confronted with invading glioma cells. At the same time, glioma cells express specific integrins and other receptors interacting with these extracellular matrix components, including receptors which are not presented in the corresponding normal cells, thus facilitating tumor cell migration and invasion (Knott et al., 1998). The relative volume of the ECM in comparison to that of cells (also referred to as the ECS volume fraction) also tends to increase, e.g., reaching $48 \%$ in grade III and IV Astrocytomas (Zamecnik, 2005); while in the normal brain this parameter is usually about $20 \%$ (Nicholson and Syková, 1998). In this regard tumors start to resemble the young brain, where the ECS volume fraction is $\sim 40 \%$. Such nonconfined conditions are believed to contribute to tumor cells ability to migrate (Zamecnik, 2005).

Glioma cells have the ability to actively migrate using blood vessels or axons as guide paths due to interaction with the ECM (Cuddapah et al., 2014). Additionally, glioma cells can secrete their own ECM components, including HA, brevikan, tenascin$\mathrm{C}$ and thrombospondin, as well as fibronectin, which are actively expressed in the ECM of the developing nervous system along cell migration paths (Bilozur and Hay, 1988). Fibronectin and HA increase the mobility of glioma cells and increase their invasiveness. Cells of high-grade gliomas synthesize hyaluronan in levels up to 20 times higher than in normal adult brain, which is comparable to or above those in fetal brain (Delpech et al., 1993). HA in tumors is also involved in cancer cells migration, as its production by tumor cells enables CD44 expressing glioma cells to migrate on hyaluronan-containing matrix, and the higher the density of CD44 receptors on cells' surface. CD44, the main cell surface receptor for HA, is thought to play an important role in altering GBM invasion through direct CD44-HA interaction (Koochekpour et al., 1995). The other hyaluronan binding proteins RHAMM and BEHAB are also expressed mostly in glioma cells, and further contribute to the invasive abilities of these tumors (Turley et al., 1994;
Seidenbecher et al., 1995). Moreover, it was demonstrated that high grade gliomas abnormally express various hyaluronidases PH-20, Hyal2 (Liu et al., 1996; Novak et al., 1999), which is not observed in corresponding normal tissues. This is especially important for the tumor front edge, where lysis of different ECM components by enzymes secreted by cancer cells is critical for their migration and tumor invasion.

Furthermore CD44 is involved in formation of tumor leading front by binding the matrix metalloproteinase (MMP) MMP9. This interaction has been demonstrated to cause degradation of the collagen IV, while cells expressing both CD44 and MMP9 can form invasive tumors (Yu and Stamenkovic, 1999). Other matrix proteinases can be found in brain tumor cells, such as urokinase-type plasminogen activator (Bellail et al., 2004). Glioblastoma multiforme cells (U251) also actively produce extracellular matrix metalloproteinase inducer (EMMPRIN), referred to as CD147, which recruits several types of metalloproteinases initially produced by surrounding stroma cells (Sameshima et al., 2000). Additionally, this mechanism activates progelatinase A (proMMP-2) which is considered to be crucial for tumor progression. Generally, cells from brain tumor prefer a denser, more structuralized than normal, state of ECM and overexpress many of its components. Though this more compact microenvironment does not seem to impede the mobility of cancer cells, as they are able to synthesize a broad set of various matrix MMPs to enlarge the pore size in matrix to provide migration routes, and have other types of adaptations to overcome confined conditions (Nyagilo et al., 2017; Paul et al., 2017).

Apart from the prominent role in cancer cell migration and invasion, matrix components form a special type of microenvironment around normal neural stem cells (NSCs), called stem-cell niche. Meanwhile, tumors have a small subpopulation of cells with an exclusive capability of recapitulating all heterogeneity of cell subclasses within a tumor. These special cells, called cancer stem cells (CSCs), are critical to formation and progression of a tumor, and considered to be a major cause of therapeutic resistance and high relapse rate (Kondo et al., 2004).

The major difficulty stems from the fact, that some components are typical to niches of both CSCs and NSCs, however, there are few unique molecular signatures specifying each of these niches' types. Additionally, expression levels of various niche components may also vary (Table 2). For instance, expression levels of a typical ECM component of young PNNs, glycoprotein tenascin-C, are shown to directly correlate with the GBM malignancy grade and patients' prognosis (ChiquetEhrismann et al., 2014; Gulaia et al., 2018).

Another example is neuroglia protein 2 (NG2) proteoglycan, also known as melanoma-associated chondroitin sulfate proteoglycan, is a membrane-anchored protein expressed by progenitor cells in the brain, especially oligodendrocyte progenitor cells. It is associated with ECM molecules, such as collagens, however NG2 is overexpressed in glioma (Wiranowska et al., 2006), and linked to migration capacity of cancer cells, since its expression levels in migratory cells are much higher than 
TABLE 2 | Components of brain stem cell niches and their expression in normal and pathological condition (based on Reinhard et al., 2016, modified).

\begin{tabular}{lcc}
\hline ECM components & $\begin{array}{r}\text { Neural stem cell } \\
\text { (NSC) niche }\end{array}$ & $\begin{array}{c}\text { Cancer stem cell } \\
\text { (CSC) niche }\end{array}$ \\
\hline Aggrecan (ACAN) & + & - \\
Brevican & + & +++ \\
Collagen & + & + \\
Fibronectin & + & + \\
Glypican-1 & + & +++ \\
Hyaluronic acid & + & ++ \\
Laminin & + & ++ \\
Neurocan & + & + \\
NG2 (neuroglia protein 2, & + & + \\
NG2 proteoglycan) & + & + \\
Perlecan & + & + \\
Phosphacan (DSD-1-PG) & - & ++ \\
Syndecan-2 (SDC2) & + & + \\
Tenascin-C & + & + \\
Versican & + & + \\
\hline
\end{tabular}

"-", not expressed; "+", expressed in normal level; "+++", overexpressed.

those of non-migratory cells (Wiranowska et al., 2006; Trotter et al., 2010).

Heparan sulfate proteoglycans (HSPGs) family membersyndecan-2 (SDC2), a membrane-anchored proteoglycan, was found to be expressed on high levels in brain tumor tissues, including gliomas, whereas never found in NSCs (Watanabe et al., 2006; Theocharis et al., 2010).

In addition, the expression of syndecan-1, glypicans, and HSPGs, which act as co-receptors for growth factors (FGF-2, PDGF, VEGF), stimulates angiogenesis and cell proliferation (Xiong et al., 2014) indispensable for tumor outgrowth.

Members of the laminin family construct NSC/CSC niches (Lathia et al., 2007). Laminins (together with collagen IV, nidogen, HSPGs, such as collagen XVIII and perlecan) mainly compose fractones, specialized ECM structures that contact NSCs (Kerever et al., 2007; Mercier, 2016). From the chemical perspective they are similar to basal membranes. Fractones, as described by Mercier, are ECM structural units, having a branched and fractal-like structure as they fill tight intercellular spaces, integrating NCSs with surrounding tissues, such as the subependymal layer. Moreover, laminin supports self-renewal of hippocampal neural stem/progenitor cells (Imbeault et al., 2009). The interaction of laminin and integrin $\alpha 6$ is shown to be important for the maintenance of NSCs/CSCs (Sun et al., 2008). However, in gliomas laminin $\alpha 2$ is produced not by glioma stem cells themselves but by non-stem tumor cells (Lathia et al., 2012).

It is widely known that CSPGs are highly expressed in the developing embryonic and adult brain as well as in glioma tissue. They influence cell mobility and axon growth and guidance (Lathia et al., 2012). Interestingly, in the adult healthy brain CSPGs exhibit inhibitory effects on stem cell migration. However, in glioma tissue upregulated CSPGs were reported to stimulate stem cell migration (Kearns et al., 2003; Sim et al., 2009). For example, CSPGs brevican and versican display significantly higher levels of expression in glioma. Both proteoglycans constitute networks comprising mesenchymal glioma-specific matrix molecules, which are not detectable in the healthy brain tissue (Reinhard et al., 2016). Brevican is especially enriched in astrocytoma and GBM, meanwhile it was demonstrated that its knockdown contributes to a reduction of late stage glioma tumor aggressiveness (Dwyer et al., 2014). Neurocan overexpression was also reported in glioma cells (Rauch, 2004; Varga et al., 2012). Other ECM components, such as hyaluronic acid, the adhesion molecule CD44 and tenascins interact with versican and stimulate brain tumor invasion. Whereas, aggrecan, another member of lecticans family, which is a typical component of the adult NSC niche alongside brevican (Mouw et al., 2014), was reported to be present only in normal NSC niches but not in CSC niches (Reinhard et al., 2016).

Thus, we can infer that many components of the normal brain ECM are overexpressed in tumor cells, which makes tumor ECM a special variety of cell microenvironment, more dense and structuralized than the rather amorphous normal brain ECM. Tumor cells, especially from glioma, demonstrate a significant set of adaptations to such confined conditions, and can successfully migrate and infiltrate into surrounding tissues. The ECM not only contributes to migration, but also plays an important role in cell survival, proliferation and differentiation processes not only in embryonic development but also in tumor growth.

\section{INTERACTION OF MATRIX MATERIALS AND NEOPLASTIC NEURAL CELLS \\ Changes in Behavior of Neoplastic Neural Cells After Interaction With the Matrix}

Currently, interaction of matrix materials and tumor cells of the neural tissue is being studied on a wide range of materials, both natural and artificial. Materials of natural origin are widely used, including (but not restricted to) those found in native ECM, such as type I collagen, hyaluronic acid, laminin, fibronectin, gelatin, alginate, as well as extracellular matrix extracts, for example, Matrigel-a laminin-rich extract of the extracellular matrix of mouse sarcoma. A significant variety of synthetic polymers that mimic extracellular matrix, such as polyethylene glycol (PEG), poly(lactic-co-glycolic acid) (PLGA), etc., are also proposed.

Development of new systems for cultivation of cancer cells is one of the methods for screening new anti-cancer drugs and studying cell-cell and the cell-ECM interactions under tumor conditions. Standard 2D culture of cells has a plurality of disadvantages and does not allow to reconstruct 3D tissue architecture that entails a discrepancy in the results of in vitro and in vivo experiments (Nyga et al., 2011; Alemany-Ribes and Semino, 2014).

It was shown that during invasion of the U87 glioma spheroid into Matrigel, spheroid cells had a compressive effect on the material, while invasive cells exerted a pulling effect on ECM (Gordon et al., 2003). 
Further study of glioma cell interaction with ECM has shown that glioma cell migration is regulated by topographic signals that affect cell adhesion and gene expression (Agudelo-Garcia et al., 2011). It has been shown that spheroid invasion is facilitated in materials containing type I collagen due to an increase in the amount of fibers available for contact interaction. However, high concentrations of type I collagen inhibit cell growth inside the matrix (Kaufman et al., 2005). Cultivating cells with collagen materials, regardless of density of the fibers, enhances expression of genes associated with stemness, cell cycle, apoptosis, epithelial-mesenchymal transition, migration, and invasiveness. Wnt, Sonic Hedgehog, and Notch signaling pathways are involved in regulating these changes (Jia et al., 2018).

Matrices created exclusively from synthetic materials are mainly used to study their mechanical properties, since such properties can be varied in large range without changing the chemical composition. To achieve this, the base material is usually covered with a substrate that is part of the ECM. For example, a study using fibronectin-coated polyacrylamide hydrogels showed that cell migration depends on the rigidity of the substrate (Ulrich et al., 2009).

It was found that metalloproteases are critically necessary for cells' invasion into the material and its degradation. For example, when modifying PEG-based matrix material, leading to complete inaccessibility of material for degradation by these enzymes, U87 cells do not form protrusions and processes, while maintaining the ability to proliferate (Wang et al., 2017).

$\mathrm{HA}$ is a major component of the brain ECM, which is also believed to alter the phenotype of the invasive glioblastoma (Akiyama et al., 2001). Adding HA to a material made of gelatin and polyethylene glycol enhances malignancy of glioma cells (Pedron et al., 2013).

Pure HA hydrogel functionalized with cysteine-phenylalanine peptide residues does not affect the viability of primary GBM cells. A hydrogel may have different rheological properties, depending on the content of components. For drug delivery, Rowland et al. suggest using a hydrogel softer than brain tissue to enhance contact at the gel-tissue interface to facilitate drug diffusion. Ex vivo injection of an anticancer drug-loaded hydrogel into resected human tissue samples demonstrated effective gel delivery and graduate diffusion of the drug into the surrounding tissue (Rowland et al., 2018).

It has been established that invasion of U251 glioblastoma multiforme cells is enhanced in softer hydrogels, but is decreased in the presence of $\mathrm{HA}$ associated with the matrix. Blocking cell-matrix interactions of HA-CD44 reduces invasion even in hydrogels that do not have hyaluronic acid associated with the matrix. To stimulate invasion, glioblastoma cells produce free $\mathrm{HA}$, thereby compensating for its lack in microenvironment (Chen et al., 2017).

Primary GBM cultures undergo significant genomic and transcriptional changes during cultivation, which should be taken into account in functional experiments and biomarker studies (Baskaran et al., 2018). Experiments on primary cultures are certainly important, but results obtained on different cells may not always be comparable even when using the same material.
An experimenter, in fact, can record not the effect of the matrix itself, but the natural transformation of the molecular profile and functional activity of cells recently isolated from the natural microenvironment of tissues and placed in vitro culturing conditions. Therefore, it will be impossible to explicitly specify the influence of the matrix itself, and not the evolution of cell populations in a culture that always occurs.

\section{Changes in Signaling and Molecular Profiles of Neoplastic Neural Cells After Interaction With the Matrix}

The above describes various ways of changing the extracellular matrix during glioblastoma progression. However, to date, little is known about the reverse effect of the extracellular matrix on cancer cells and development of tumors in response to changes in microenvironment.

3D culturing of U87, U251, and HS683 glioma cells using collagen showed an increase in expression of stem markers, such as CD133, Oct4, Sox2, and Nanog; cycle-related genes p21 and p27, genes related to the epithelial-mesenchymal transition (Ncadherin and vimentin) and invasion (MMP1, MMP2, MMP3, and MMP7), anti-apoptotic factors (PDL-1 and Livin), and a decrease in expression of pro-apoptotic factors, including caspases, poly (ADP-ribose) polymerase (PARP), and p53 (Jia et al., 2018).

In the study using poly- $\varepsilon$-caprolactone nanofibers as a substrate for cultivation, authors showed that glioma cell lines U87 and U251 demonstrate an extended morphology of cells migrating into the white matter tissue and are very sensitive to inhibition of myosin II in contrast to same cells cultivated on standard polystyrene. In this case, an increase in cell migration activity was achieved through the activation of STAT3 signaling, a known driver of glioma progression (Agudelo-Garcia et al., 2011).

An example of tumor growth activation in response to the extracellular matrix is shown in the work using chitosan-alginate materials (Kievit et al., 2014). After culturing cell lines U$87 \mathrm{MG}$ and U-118 MG on these matrices cells acquired CD133 ${ }^{+}$ phenotype and showed increased expression of Nestin and $\mathrm{N}$ cadherin as compared to the conventional method of cultivation. Moreover, the growth of xenograft tumors in nude mice was significantly higher, when cells were used after cultivation with chitosan-alginate materials, which demonstrates importance of the effect of the matrix on the tumor cells.

Human glioblastoma cells U87, cultured on chitosanpolycaprolactone composite nanofibers, enhance migration and demonstrate activation of genes associated with invasion including $\beta$-catenin, Snail, STAT3, TGF- $\beta$, and Twist (Kievit et al., 2013).

Glioblastoma cells of patients with different expression of EGFR (EGFR wild type, EGFR ${ }^{+}$, and EGFRvIII) were studied in a culture model using matrix hyaluronic acid (HA) decorated with methacrylamide-functionalized gelatin (GelMA) (Pedron et al., 2017). It has been shown that phenotypically different tumors require extracellular matrix of different composition for the activation of key genes. Thus, for EGFR wild type cells, increased 
expression of VEGF, MMP-2, MMP-9 FN, and HIF-1 occurs at low concentrations of HA, and EGFR + cells require a high concentration of HA. Moreover, authors showed that binding of CD44 to HA leads to the activation of EGFR in EGFR wild type and $\mathrm{EGFR}^{+}$, and the presence of $\mathrm{HA}$ in the matrix increases the resistance to tyrosine kinase inhibitor in EGFRvIII cells.

Not only the chemical composition of the extracellular matrix, but also its rheological characteristics, significantly moderates behavior of cancer cells. In the study using chitosan-HA scaffolds, authors showed that denser and stiffer materials lead to higher drug resistance in U-87 cells against temozolomide, increase the expression of chemoresistance markers (ABCG2), hypoxia inducible factor (HIF-1 $\alpha$ ), and invasion (CD44, MMP-2) (Erickson et al., 2018).

Despite development of methods for the treatment of malignant brain tumors, lifespan of patients with glioblastoma after surgical resection of the tumor rarely exceeds 15 months (Pinto et al., 2008). In this regard, in recent decades, the number of works aimed at developing alternative methods for drug delivery achieving direct effect on tumor cells based on biomaterials has increased.

However, currently there are very few works focuses on in-depth analysis of the action mechanisms of developed biomaterials on signaling pathways in glioblastoma cells.

Suppressing proliferation and reducing viability of human glioma cells U87 and U118 in vitro and in vivo resulting in reduction of tumor volume was observed in the work with the use of graphene plates (Jaworski et al., 2015). The authors of this work noted a high level of apoptosis in treated cells associated with the activation of proapototic gene CASP-3. In the study conducted with the use of hydrogels based on cellulose produced by bacteria Komagataeibacter hansenii, authors showed the ability of this material to attract and retain F98 glioblastoma cells; they offer to use this material together with chemoattractants for tumor cells for implantation in the area of tumor resection (Autier et al., 2019).

In addition to the anti-cancer effect, implantable materials should have a regenerating anti-inflammatory and neuroregenerative effect after surgical resection of the tumor. Currently, there are many works devoted to the regeneration of nervous tissue. Materials that promote regeneration are of both synthetic and natural origin. In the work with the use of polymeric ethyl acrylate and hydroxyethyl acrylate matrix in vivo, it was demonstrated that this material is populated after the implantation into the rat brain with cells of both glial and neuronal types (Martínez-Ramos et al., 2012). Scaffolds composed of electrospun poly-1/dl lactic acid (PLA70/30) nanofibers with Young's modulus around $140 \mathrm{MPa}$ support the growth of glia and brain neurons and promote vascularization in vitro and in vivo, unlike non-aligned nanofibers with Young's modulus in the region of $40 \mathrm{MPa}$ (Álvarez et al., 2014). Another study focuses on PEG-based hydrogels causing less astrocytic reaction in the injured brain compared to controls (Bjugstad et al., 2010). Poly $\varepsilon$-caprolactone matrices with brain derived neurotrophic factor (BDNF)-mimetics are able to be actively infiltrated with neuroblasts which further differentiate into neurons at the site of brain damage (Fon et al., 2014).
Numerous hydrogel types based on natural substances and their modifications are proposed today for regeneration of damage to both the spinal cord and the brain. In another study it was shown, that agarose hydrogels loaded with BDNF promote axon growth and demonstrate an anti-inflammatory effect in spinal cord lesions, compared to pure agarose (Jain et al., 2006). Alginate-based hydrogel with glial-derived neurotrophic factor causes functional restoration of the rat spinal cord hemisection model (Ansorena et al., 2013), and alginate-gelatinbased hydrogel has a stimulating effect on axonal growth in neurons of the cerebral cortex in vitro (Pawar et al., 2015).

Cancer cells respond not only to qualitative and quantitative changes in the microenvironment, but also to changes in mechanical properties of the extracellular matrix. Based on Hrapko's review of studies done over the past 50 years which focus on mechanical characteristics of the brain, it can be assumed that the values for $\mathrm{G}^{\prime}$ and $\mathrm{G}^{\prime \prime}$ vary in the range from 100 to $104 \mathrm{~Pa}$ and from 20 to $1,000 \mathrm{~Pa}$, respectively, depending on the method and conditions of measurement (Hrapko et al., 2008).

In the work with the use of polyacrylamide gels with a modulus of elasticity in the range from $300 \mathrm{~Pa}$ to $14 \mathrm{kPa}$, glioblastoma cells LN229 occupied the larger area, the harder polyacrylamide gels was on the cultivation surface. At the same time, normal astrocytes were less responsive to changes in the modulus of elasticity of the substrate. The authors did not discover any differences in mechanical properties of biopsy specimens of gliomas and healthy brain and suggested that increased stiffness due to vascularization and interstitial pressure in gliomas in situ may cause same reactions associated with increased substrate stiffness in vitro (Pogoda et al., 2014).

It is currently known that adult glioma aggression and patient prognosis may correlate with the stiffness of ECM (Miroshnikova et al., 2016). In general, non-tumor tissue shows the lowest level of ECM rigidity, while lower grade gliomas and GBM are more rigid; although there is heterogeneity between patients. Cell heterogeneity is consistent with the status of the isocytrate dehydrogenase-1 (IDH1) gene, since IDH1 is metabolic an enzyme which mutation is associated with greater survival without tumor progression (Gulaia et al., 2018). Most lower grade gliomas have a mutant IDH1, while GBM rarely carries such a mutation. Rigid GBM tumors with wild-type IDH1 have an impaired vasculature, leading to hypoxia, the emergence of necrotic foci, and signal transduction via hypoxia-induced factor$1 \alpha(\mathrm{HIF} 1 \alpha)$, a transcription factor that acts as the main effector of hypoxia. HIF $1 \alpha$ binds directly to the tenascin- $\mathrm{C}$ promoter inducing its transcription (Miroshnikova et al., 2016). TenascinC modifies ECM by binding lecticans. Modification leads to the densification of tumor tissue relative to the normal brain, because lecticans are non-covalently bound to HA (Mouw et al., 2014). The IDH1 mutation reduces the susceptibility of glioma cells to hypoxia, which leads to a decrease in the production of HIF1 $\alpha$ and tenascin- $\mathrm{C}$, thereby reducing tumor aggressiveness.

Previously mentioned facts indicate that implantable materials can also be used as delivery vehicles for nerve stem cells and committed precursors of nerve cells. At the same time, the material simulates the biomechanical properties of the native tissue, supports the vital activity of the replacement 
cells and provides a contact guide for the directed growth of axons (Ghasemi-Mobarakeh et al., 2008; Yang et al., 2015). Moreover, materials are able to control cell fate, prevent the uncontrolled division of cells and determine the direction of their differentiation (Scanga et al., 2010; Wang et al., 2010).

Surgical removal of the tumor often leads to the postoperative complications including iatrogenic stroke (16.3 per 1,000 cases), hemorrhage or hematoma ( 10.3 per 1,000 cases) and other nervous system complications (8.2 per 1,000 cases). The mortality of the patients upon the occurrence of any surgical complications after resection of the tumor increases 4.4 times (De la Garza-Ramos et al., 2016). Thus, the issue of postoperative recovery and rehabilitation is quite acute. Based on cellular signaling and the difference in cell behavior depending on the stiffness of the matrix, we offer a two-step method in the treatment of gliomas. At the first step after removal of the tumor, the resection cavity should be filled with a relatively soft matrix with the addition of anti-cancer drugs inhibiting key oncogenic pathways, while the relatively soft matrix will help inhibit the growth of cancer cells because of its stiffness. After the proven success of the application of the first matrix, it can be replaced with a tougher matrix with the addition of the factors that stimulate the nervous tissue repair, as noted earlier, the matrices with relatively high rigidity stimulate the neurite outgrowth.

\section{VARIOUS STRATEGIES FOR THE TREATMENT OF GLIOBLASTOMA USING BIOCOMPATIBLE MATERIALS AND PROSPECTS FOR THEIR USE}

When a matrix material is loaded with a drug, it is possible to significantly increase the life expectancy of patients after resection of glioblastoma and potentially eliminate it completely (Furnari et al., 2007). However, the in vivo implantation in the brain has several limitations:

(1) Tumors in the brain are often localized near vessels and nervous tissue. In more than $90 \%$ of cases, relapse occurs at the edges of the resection cavity or within a few millimeters of the resection cavity.

(2) There are several barrier systems in the brain that interfere with the delivery of cytotoxic drugs to tumor sites. Any damage to these barriers can lead to serious consequences.

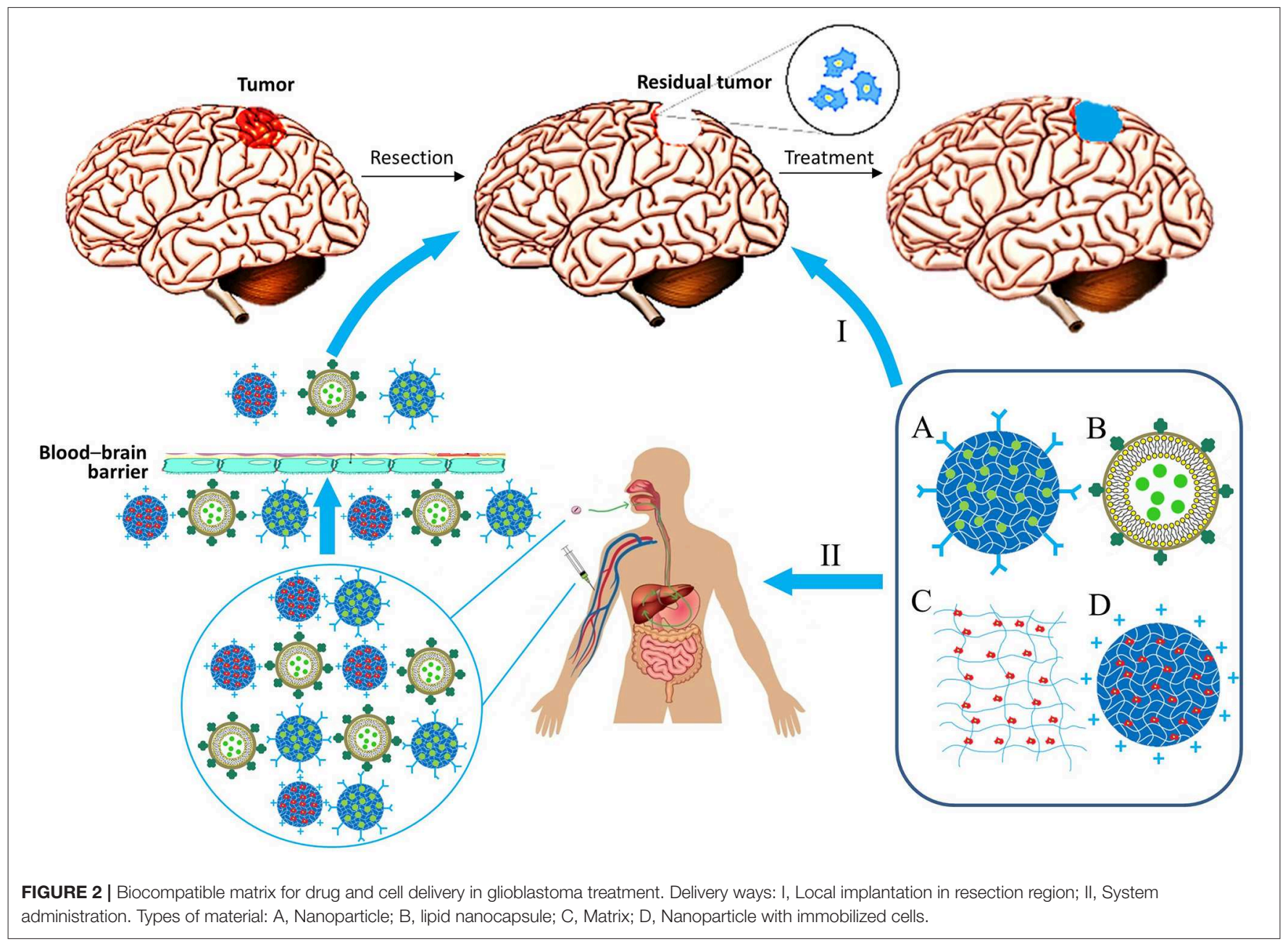


(3) The high degree of heterogeneity of GBM leads to variability in histopathology and the inability to reliably predict the response of the tumor to therapy.

(4) The rapid and uncontrolled proliferation of GBM cells in combination with the above-mentioned properties allows the tumor to quickly develop resistance to apoptosis and chemoresistance, which usually leads to death for the patient.

To solve these problems and achieve the best outcome for a patient, many different strategies have been developed, like inventing barrier-penetrating drugs or changing the permeability of barriers in various ways (Bastiancich et al., 2016a, 2017; Zhao et al., 2018).

The main types of materials proposed for the treatment of GBM are:

(1) Polymeric micelles are the particles of matrix formed by selfassembly of amphiphilic copolymers. They have a structure consisting of a hydrophilic shell and a hydrophobic core capable of absorbing and encapsulating poorly soluble drugs. Therefore, they are widely used as drug delivery systems in various therapeutic areas, including cancer treatment, in particular glioblastoma (Morshed et al., 2013; Yang et al., 2016).

(2) Polymer nanoparticles comprising distinct type of material existing in several different variants, and many others are currently being developed. Their structure provides the ability to enclose drugs in particles or bind them to their surface. These materials, using various types of ligands, can be conjugated to magnetic nanoparticles, thus forming a more advanced type of matrix for targeted therapy (Bennet and Kim, 2014; Nam et al., 2018).

(3) Lipid-based drug delivery systems (nanoparticles, micelles, liposomes) can be used to deliver drugs with poor water solubility. They can improve the bioavailability of such drugs and gradually release them over a long period of time. The great advantage of these systems over other drug carriers is their lower toxicity (Müller et al., 2002).

(4) Hydrogels, constructing a three-dimensional (3D) polymer network, can absorb large amounts of water or biological fluid without dissolving the polymer due to its hydrophilic, but elastic structure. Therefore, polymeric matrices are able to encapsulate various biomacromolecules, similar to drugs, and gradually release them in a controlled manner over a long period of time (Bastiancich et al., 2016b).

(5) Magnetic particles are nanoparticles made on the basis of gold, silver and gadolinium bringing up the most promising approach for the GBM treatment. A powerful magnetic field pulls drug particles out of suspension and delivers them to a localized site of the disease. Furthermore, magnetic particles are used to treat cancer by means of hyperthermia, as after reaching the tumor location, they are heated by an alternating magnetic field and thus thermally kill cancer cells (Maier-Hauff et al., 2007; Mahmoudi et al., 2018).

Materials consisting of small-sized particles (nanoparticles, micelles, and liposomes) can be delivered by injection into the bloodstream. Alternatively, it is possible to incorporate them into other gel materials, which can be injected directly into the site of tumor resection, or the delivery can be performed intragastrically (Wang et al., 2016). In this regard, matrix therapy can be largely divided into systemic and local (Figure 2).

Systemic therapy, as previously mentioned, can be accomplished by introducing the matrix intravenously or intragastrically with its subsequent delivery by the bloodstream across the blood-brain barrier (BBB). Many materials are capable of penetrating the $\mathrm{BBB}$ by themselves because of adsorptive-mediated transcytosis, when a particle is positively charged, so it binds to the surface of an endothelial cell and gets absorbed by it to be exocytosed on the surface of the lumen. However, ability of materials to overcome BBB can be further improved for effective treatment of brain cancers. Ability of nanoparticles/micelles to penetrate the blood-brain barrier is usually associated with the presence of certain peptides on their surface or antibodies specific for receptors on the surface of barrier cells (Pulgar, 2018). Some of the most important aforementioned receptors are the transferrin receptor, the insulin receptor, lipoprotein receptors, and folate receptors (Furtado et al., 2018). For instance, epirubicin liposomes modified with transferrin or tamoxifen significantly improved the efficacy of the anticancer drug in a rodent model of brain gliomas (Tian et al., 2010). Interestingly, it is feasible to bring carriers across the BBB by the cellular transport, e.g., the surface of the carrier is modified to improve phagocytosis by immune cells which then deliver particles through the BBB to the target location. This method can be further advanced by changing electrostatic and hydrophobic adsorption properties for phagocytosis activity improvement, ligand-receptor attachment, covalent coupling, and internalization (Stephan and Irvine, 2011). Physical and chemical properties of particles, such as size, shape, and type of material are also important for their effectiveness (Champion and Mitragotri, 2006; Albanese et al., 2012). Particles of materials can be covered with cellular membranes (e.g., erythrocyte membranes) for their "masking" to facilitate delivery through the BBB (Chai et al., 2017). With this delivery strategy, nano-sized particles are not required (Jain et al., 2003).

All of the described methods of overcoming the BBB for delivery of matrices are summarized in the Figure 3.

However, systemic therapy has a number of disadvantages, modified from Srivastava et al. (2016):

(1) Oral administration may result in degradation of the drug by the gastrointestinal enzymes or by its metabolization and inactivation in the liver.

(2) Bloodstream administration of the matrix may trigger phagocytes and result in elimination of a large portion of particles.

(3) Particles composed of hydrogels can quickly absorb the surrounding water possibly leading to premature drug release.

(4) Utilization of nanoparticles implies specific shell and core construction, which should be immiscible, that further complicates microspheres production and design of their architecture. 


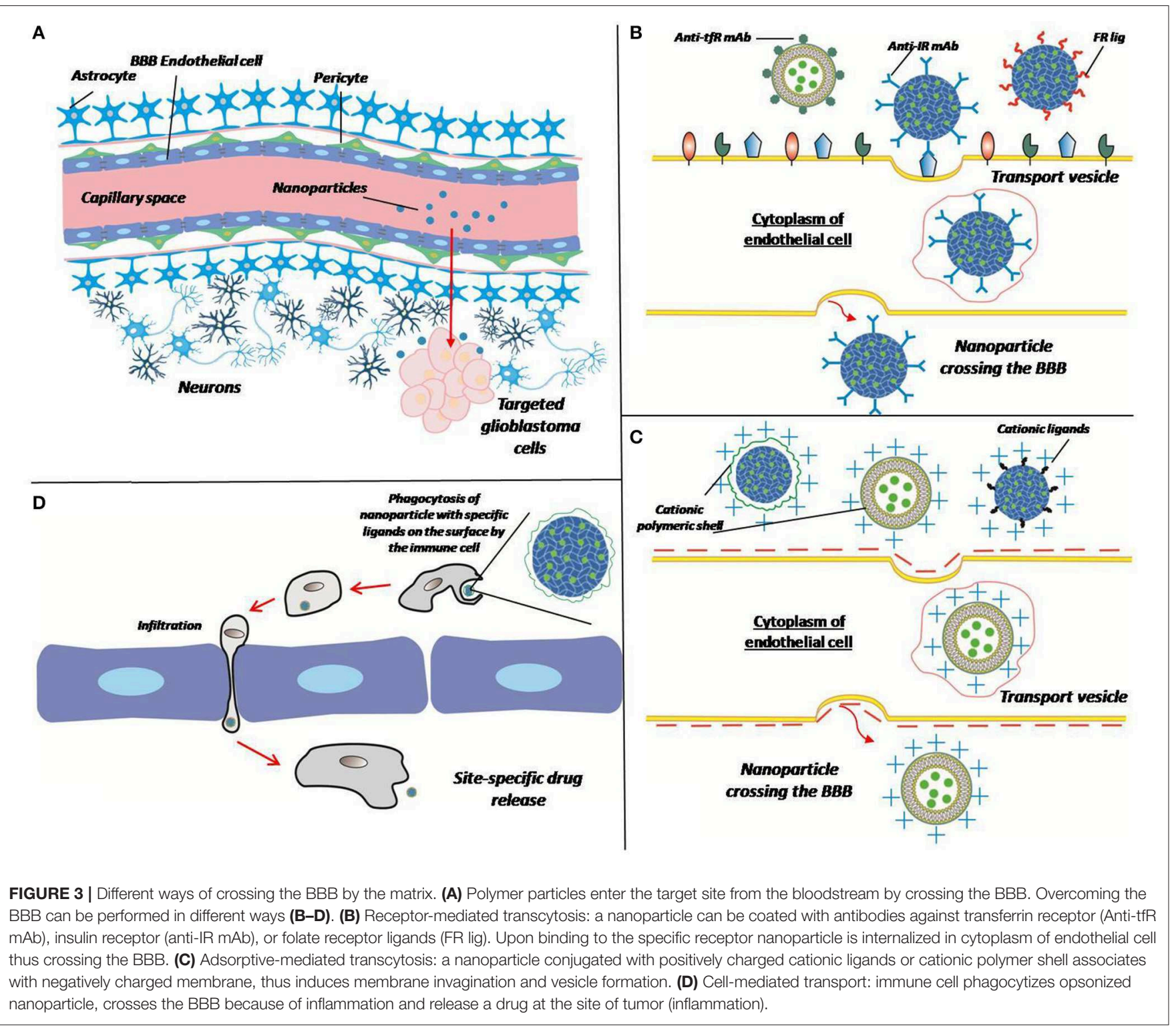

(5) The complexity of a reliable system development that could precisely control drug release from a depot.

(6) The difficulty of creating successful designs for drug delivery through various barrier systems.

(7) The systemic therapy requires the distinct way of matrix production inferring large volumes and high cost (Kim and Pack, 2006).

Thus, the most promising therapeutic strategy is local delivery of therapeutic agents into the brain cavity formed after the removal of a malignant neoplasm. This method does not have most of the drawbacks described above (matrix substances are introduced during the operation into the resection cavity, without affecting the CNS barriers and vessels). In addition, it helps to fill the gap in the course of the therapy between the operation and chemoradiation therapy (without impeding the process of operational wounds healing) (Bastiancich et al., 2017; Zhao et al., 2018). Further, we review the development of this strategy in more detail.

\section{DEVELOPMENT OF IMPLANTS FOR LOCAL CHEMOTHERAPY}

This strategy is based on the implantation of matrix materials (gels, nanoparticles, films, disks, rods, plates, etc.) and further gradual release of a drug into the surrounding brain tissues over a long period of time. During the release of the drug, matrix material should get decomposed to monomers suitable for metabolization or evacuation. If it is not biodegradable, there should be a possibility to remove matrix material. It must also gradually, over a long time period, release the drug in prescribed doses for effective action on tumor cells. The drug should 
have maximal possible effectiveness against cancer cells, good diffusion potential to prevent tumor relapse in remote areas, and should not cause chemoresistance in cancer cells. Importantly, the matrix itself and the drug should be hypoallergic to prevent possible therapy complications (Bastiancich et al., 2016a; Puente et al., 2018; Pinel et al., 2019).

This paper is focused mostly on hydrogels, because these polymer structures comprising the cutting-edge field of the most popular and promising tools for medical and biological manipulations. Hydrogels are injected directly into the brain after tumor resection via intracerebral implantation or intracerebroventricular injection.

Currently, Gliadel ${ }^{\circledR}$ plates are the only implant approved by the US Food and Drug Administration (FDA) and the European Medical Agency (EMA). This is a biodegradable copolymer formed from 1,3-bis-(p-carboxyphenoxy) propane Saito(pCPP) and sebacic acid in a 20:80 ratio (polyfeprozan 20), impregnated with a chemotherapeutic drug BCNU (Carmustine) (Saito et al., 2017). The advantages of this implant are low systemic toxicity (reducing effects of gastrointestinal disorders, asthenia, fever and depression), gradual release of the drug over a period of time, and an increase in the long-term overall survival of patients (Xing et al., 2015). Disadvantages of this implant are serious local side effects, which include convulsions, intracranial hypertension, meningitis, swelling of the brain (causing repeated surgical intervention). The plates are poorly fixed and can migrate to other parts of the brain, which impairs wound healing. It was also demonstrated on model organisms that a larger portion of the drug is released in the first 5-7 days, and the range of the drug effect extended only barely beyond the polymer interface (3-6 mm during the first 7 days, $2-3 \mathrm{~mm}$ for the next 2 weeks); remote parts of the brain displayed insignificant concentrations of the drug. Although carmustine showed good results in treating tumor cells, temozolomide (TMZ) is more effective in treating malignant primary brain neoplasms, and therefore the choice of a drug for Gliadel ${ }^{\circledR}$ is not considered to be the most optimal. In addition, only one third of GBM patients responded to carmustine treatment (Saito et al., 2017).

In connection with aforesaid facts, taking Gliadel ${ }^{\circledR}$ errors into consideration, further developments are aimed at improving basic parameters of matrix and drug, as well as at increasing the functionality of these implants (Bastiancich et al., 2016a). Due to the fact that cancer cells go through various phases in tumor development and post-operational dynamics, which are characterized by shifts in cell microenvironment, they require different treatments strategies. Thus, we propose a novel approach to GBM treatment, described below.

We suggest that the scientific community and cancer therapists draw the attention to the possibility of developing a two-stage approach to the treatment of particular glioma cases. Taking into account advantages of 3D cell cultivation on the one hand, and the heterogeneity of gliomas on the other, it can be concluded that there is a demand for development of a biocompatible matrix, aimed at the direct delivery of anticancer drugs, blocking key molecular participants in carcinogenesis, and regeneration of healthy nervous tissue after tumor resection.
These two opposite processes can be applied in two successive stages (Figure 4):

(1) Filling the post-operative cavity with the matrix possessing a relatively low modulus of elasticity loaded with anticancer drugs, preventing hypoxia, and aiming at inhibiting key prooncogenic pathways (inactivating synthesis of cd133, vegfr, $\beta$-catenin, snail, stat 3 , tgf- $\beta$, twist etc.).

(2) Substitution for a matrix with a higher modulus of elasticity, loaded with brain derived neurotrophic factor or its analogs enabling the sprouting of nerve cells.

Carcinogenesis is known to be frequently associated with the development of cognitive impairments [from 25 to $44 \%$ depending on the particular impairment (Armstrong et al., 2006)]. Some cognitive dysfunctions, such as poor verbal memory and executive dysfunction can either persist after surgery (Veretennikoff et al., 2017) or undergo remission to some extent (Dhandapani et al., 2016). The two-stage approach is aimed at improving the quality of life for such patients; however, the patient's safety and the increathe of his life expectancy should remain the priority in the fight against tumors in general and gliomas in particular. In this context, if the risk of matrix delivery to the tumor site located in a hard-to-reach region exceeds the potential positive therapeutic effect, then the two-stage approach should be abandoned. If the tumor is located in a surgically "safe" area, then the first stage can be implemented after the standard chemotherapeutic course; e.g., the introduction of a matrix with the relatively low elastic modulus, that is loaded with antitumor drugs and/or cytostatics against key oncogenic pathways. We propose an elastic modulus $\leq 1,000 \mathrm{~Pa}$ for the first stage, since this elasticity does not stimulate the outgrowth formation and is able to suppress cell proliferation (Klein et al., 2009), while for the second stage we recommend an elasticity modulus $\geq 1,000 \mathrm{~Pa}$ to simulate neurite regeneration (Klein et al., 2009; Pogoda et al., 2014). The duration of the first stage should be approximated in accordance with the anticancer drug release time and the time of matrix biodegradation (in case of the biodegradable matrix), for instance, Gliadel ${ }^{\circledR}$ wafers completely degrade during 6-8 weeks (Wu et al., 1994). Thus, we suggest calculating the first stage time in accordance with the duration of the matrix biodegradation, however, the rapid and uneven release of the loaded drug (Grossman et al., 1992) could be the reason to adjust the calculation. The frequency of relapse after tumor removal is quite high-around $50 \%$, and the most frequently it occurs within the resection cavity on the average from 6-9 (Mallick et al., 2016) to 17 months (Konishi et al., 2012). In case of using a nondegrading matrix at the first stage, it should be removed from the resection cavity and replaced with a matrix with a higher elastic modulus loaded with the brain derived neurotrophic factor or its analogs. Since the first stage is specifically aimed at protecting the patient from a relapse as well as at destroying remained proliferating cancer cells near the resection cavity, we suggest that a 6 -months period between the stages will be optimal and should be taken to monitor the patient for a possible relapse. There is a certain risk of relapse initiation by a matrix loaded with the brain-derived neurotrophic factor or its analogs due to 

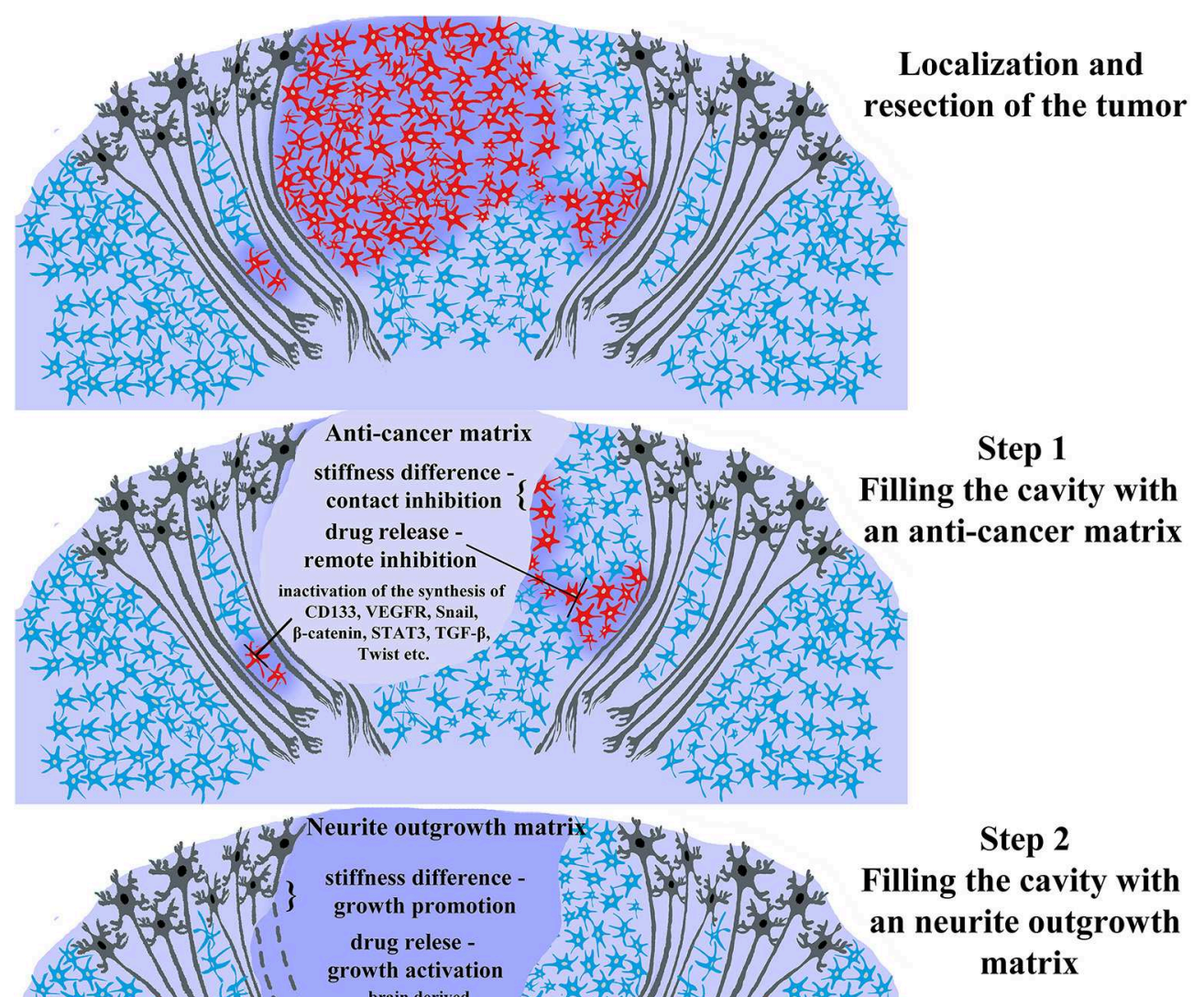

Step 1

illing the cavity with an anti-cancer matrix

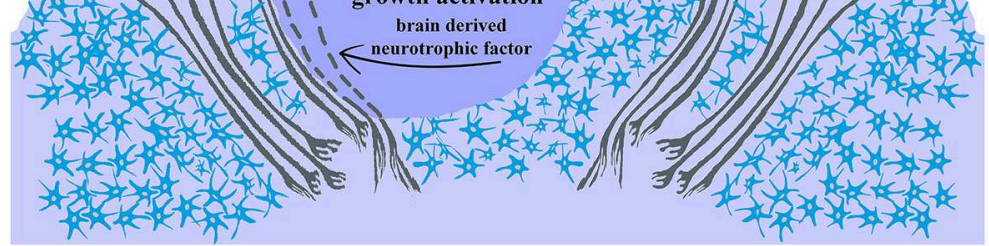

\section{Matrix stiffness \\ tougher}

softer

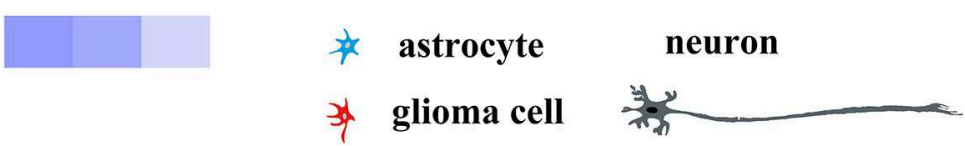

FIGURE 4 | Promising therapeutic strategy for gliomas treatment using 2-step biomaterial insertion. The upper picture displays tumor consisting in red cells and surrounding tissue comprising normal glia cells (blue) and normal neurons (dark gray). The tumor has a primary lesion and diffusely infiltrating branches on the sides. After tumor localization and resection, the post-operative cavity can be filled with anticancer soft matrix (the middle picture) containing chemotherapeutic drugs capable of killing residual tumor cells and/or inhibiting main cancer associated pathways (CD133, VEGF, Snail, $\beta$-catenin, STAT, TGF- $\beta$, Twist). This soft matrix will prevent rapid regrowth of tumor cells as it physically occupies the cavity and release the chemotherapeutic drug killing infiltrated tumor cells left in brain parenchyma. Upon the first gel biodegradation and complete drug release, the cavity will be filled by the filled with the second denser matrix facilitating wound healing and neuron axon regrowth (the lower picture). The last step is necessary for avoiding scar formation and faster rehabilitation from prospective neurological complications after the surgery.

the remaining "quiescent cancer stem cells," however, there is a theory suggesting that proliferative stimulation of these cells can increase their sensitivity to anticancer drugs (Gulaia et al., 2018). On the one hand, the first stage is aimed specifically at protecting the patient from relapse and killing the remaining cancer cells near the resection cavity, on the other hand, the second stage employs the matrix stimulating the nerve tissue growth and has antagonistic properties compared to the first stage matrix. In addition to certain requirements for elasticity, the second stage material should have specific biodegradation rate optimal for nerve tissue regeneration. Many experimental data available for tissue regeneration in the stroke models prompt us to suggest a period of 3-4 months for the second stage (Cook et al., 2017; Ghuman et al., 2018; Nih et al., 2018). 
Thus, we propose a unique approach employing the usage of two matrices subsequently, in the way, that first matrix prevent the tumor regrowth as the absence of empty space and prolonged drug release will hinder this process, while the second matrix possessing denser structure will allow neurons to regrow their damaged axons and dendrites. Therefore, the latter matrix will be implemented for faster recapitulation of neurological consequences from surgery.

In addition, further we review the latest trends in the creation of matrices and implants for the treatment of GBM.

\section{VARIOUS POLYMER MATRICES USED FOR DRUG DELIVERY}

\section{Fully Synthetic-Based Matrices}

Drug delivery in case of GBM could be hindered by BBB preventing therapeutic drugs and small molecules reaching the tumor growth site. The polymeric matrices are promising in terms of biocompatibility and prolonged drug delivery time. This group includes polymeric materials that are synthesized from various monomers and have little or no effect on cell niches.

\section{PLGA-Based Matrices}

PLGA is a biodegradable and biocompatible polymer that is used in a number of FDA-approved therapeutic devices (grafts, sutures, implants, prosthetic devices, surgical sealant films, etc.). PLGA biodegradable nanofibers can release high concentrations of vancomycin for more than 8 weeks in the cerebral cavity of rats (Tseng et al., 2013). A number of publications reported that it can be used for the treatment of brain tumor as an alternative drug delivery system (Bagó et al., 2016; Ramachandran et al., 2017; Zhao et al., 2018). Modification of PLGA with copolymer Poloxamer 188 renders it the capability of penetrating BBB more effectively (Malinovskaya et al., 2017). Despite the large number of studies, systemic toxic effect of the drugs delivered by the PLGA nanoparticles remains not fully understood and requires further research.

One of the most effective and easy to produce of the biodegradable gel matrices for the delivery of TMZ was developed in 2008 by Akbar et al. It consists of PLGA plasticizers (40:60) loaded with temozolomide; the plasticizers themselves consist of acetyl triethyl citrate and triethyl citrate (30:30). The authors developed a surgical resection model of intracranial glioma C6GFP in rats to test this matrix in vivo. Introduction of implants loaded with $30 \%$ TMZ resulted in a decrease of the tumor size by $94 \%$, accompanied by a slight decrease in animal weight and neurological activity. The implants used demonstrated complete biodegradability and efficiency, and continued drug delivery to the peritumoral areas beyond a 15-days period (Akbar et al., 2009).

In 2011, Ozeki et al. developed microspheres containing thermoreversible gelation polymer TGP hydrogel with camptothecin (CPT), and evaluated its therapeutic efficacy (comparison of survival) on the C6 glioma model and a tumor resection model. Treatment with CPT/PLGA/TGP showed significant survival compared with the untreated rats ( 26 vs. 18 days, respectively). Similar therapeutic effects were observed in groups that received only CPT/PLGA/TGP and surgical tumor resection plus CPT/PLGA/TGP, but some long-term survivors (>60 days) were observed in this latter group, which means that combination therapy may be a good strategy for this hydrogel. At the same time, ICG fluorescence in the ICG/PLGA/TGP remained localized for 28 days after injection. Moreover, neither significant body weight loss nor aggressive immune response were observed (Ozeki et al., 2012).

\section{PEG-Based Matrices}

PEG as a component of hydrogels enhances the absorbance of water-soluble substances. Presence of a controlled pore size makes it a suitable carrier for targeted drug delivery. The potential of this material in treatment of spinal injuries is being studied (Isa et al., 2015). Mostly, PEG is used in combination with PLGA.

Another interesting implant based on PLGA and PEG is OncoGel $^{\mathrm{TM}}$. This hydrogel was tested in 2008 by Tyler et al. as an adjuvant for radiotherapy on an intracranial model. OncoGel ${ }^{\mathrm{TM}}$ consists of Cremophor ${ }^{\circledR}$ EL-based paclitaxel immersed in $\mathrm{ReGel}^{\mathrm{TM}}$, which is a copolymer of PLGA and PEG. With the change in temperature from room to normal body, the viscosity of the matrix is shifted to high thus forming a gel once inside body. Viscosity change comes along with the modifications in other properties, e.g., matrix turns into biodegradable gel insoluble in water with controlled release of the drug. Tests on model organisms showed an increase in median survival with $37.5 \%$ of long-term survivors and the absence of toxicity and any pathological changes. At the same time, ReGel loaded with paclitaxel is biodegradable and releases paclitaxel at a constant rate for $\sim 50$ days (Tyler et al., 2010).

In 2010, the thermally reversible gel-forming polymeric hydrogel TGP (Mebiol ${ }^{\mathrm{TM}} \mathrm{Gel}$ ) was developed. This matrix exhibit unique properties as it has a liquid form at room temperature, while become a gel once the temperature rises to normal body one. It consists of PEG conjugated with thermosetting polymeric poly-N-isopropylamide. TGP is biocompatible, non-cytotoxic, and completely pathogen-free. Tests were performed on a human GBM subcutaneous xenograft model demonstrating significant inhibition of tumor growth during drug encapsulation. Drug releases from TGP-dox combined with sphere- dox or lipo-dox lasted for 32 and 38 days, respectively (Arai et al., 2010).

An interesting representative of a photopolymerizable hydrogel is a type of injectable matrix described in 2015 by Fourniols et al. This matrix consists of a mixture of PEG dimethacrylate (PEG-DMA) and water (75:25), as well as $0.5 \%$ Lucirin-TPO ${ }^{\circledR}$ as a photoinitiator. When this mixture is exposed to $400 \mathrm{~nm}$ light for $15 \mathrm{~s}$, the matrix quickly changes its properties $(<2 \mathrm{~min})$ and acquires a viscosity modulus of around $10 \mathrm{kPa}$. Studies conducted in model animals showed that the hydrogel does not cause apoptosis in the brain of mice and has no impact on the activation of microglia, while the antitumor effectiveness in mice treated with photopolymerized hydrogel was significantly enhanced compared to conventional drug delivery (Fourniols et al., 2015). 
In 2018, an injectable photopolymerizable PEG-DMA hydrogel was developed and characterized by Zhao et al. It was synthesized using a modified emulsion diffusion procedure containing exclusively photopolymerizable PEG-DMA loaded with Paclitaxel (PTX) PLGA-nanoparticles. In vivo tolerability studies showed that implantation of hydrogel into brains of healthy mice was well tolerated for the short time period (1 week) as well as for the long period (4 months). Studies of in vivo antitumor efficacy carried out on a clinically relevant tumor model (orthotopic model of U87 resection in mice) showed that PTX PLGA-nanoparticles significantly prolonged the survival of mice, and $50 \%$ of mice were alive 5 months after tumor implantation (Zhao et al., 2018).

\section{Other Matrices}

In another study, the matrix comprising doxorubicin elution granules was evaluated for safety and efficacy on the 9L glioma model. This matrix consists of microspheres composed of modified polyvinyl alcohol with sulfonate groups mixed with the $0,6 \%$ alginate solution. Additionally, one can choose a therapeutic agent for this matrix, for example, between irinotecan, topotecan and mitoxantrone. Studies on model organisms showed significant results compared with untreated animals in terms of survival (44, 54, and 26 days, respectively), accompanied by the absence of significant immune response and weight loss. Also, studies have shown that doxorubicin was still released from the beads at 90 days point after implantation (Vinchon-Petit et al., 2010).

A notable example of a $\mathrm{pH} /$ temperature-sensitive matrix is a magnetic nanogel, tested in 2010, which contains contrast media for MR and fluorescence imaging. This matrix consists of $\mathrm{N}$-isopropylacrylamide-co-acrylic acid nanogel loaded with superparamagnetic iron oxide (SPIO) nanoparticles that have been conjugated with Cy5,5-lactoferrin. This implant was tested for the treating of rat glioma C6 tumors in vivo. The grafted fluorophore Cy5,5 is responsible for fluorescent imaging, SPIO helps to detect nanoparticle accumulations in brain tumors, while lactoferrin is a ligand for protein 1 linked to a low-density lipoprotein receptor which is overexpressed in GBM. Likewise this matrix was proved not to cause inflammation and significant weight loss (Xie et al., 2011; Jiang et al., 2013).

\section{Matrices Based on Natural Compounds}

Natural matrices contains polymeric materials in which the matrix backbone is partially or completely composed of substances isolated from living organisms or synthesized on the basis of natural compounds.

Chitosan is a 1,4-linked 2-amino-2-deoxy- $\beta$-D-glucan which can be cleaved by lysozyme in animals, thus possessing the advantage of natural in vivo biocompatibility and biodegradability. Xie et al. synthesized stearic acid with grafted chitosan and investigated the physicochemical characteristics of obtained micelles. The material showed promising results in in vivo studies of glioma C6 treatment (Xie et al., 2012).

Alginates are alginic acid salts. Unlike the insoluble alginic acid, potassium and sodium alginates form colloidal solutions in water. Addition of sodium alginate water solution to solutions containing calcium ions (e.g., $\mathrm{CaCl}$ ) leads to the formation of insoluble calcium alginate gels. Alginates are non-toxic, and also highly compatible with microenvironment in the brain (Lee and Mooney, 2012), so its microcapsules can be used to immobilize and deliver peptides with anticancer activity to the brain (Read et al., 2001).

Dextran is a branched glucose polymer with an average weight of chains ranging from 3 to $20,000 \mathrm{kDa}$. The main chain consists of molecules linked by the $\alpha-1.6$ bond, and side branches are attached by $\alpha-1.3$ bonds. When used as matrices, dextrans are coated with iron oxide nanoparticles to make its aqueous solution a stable dispersion systems. Currently, dextran platforms are being developed for the controlled release of doxorubicin in the treatment of GBM. Preliminary studies have shown that such matrices are superior to polylactic acid based materials in preventing the recurrence of glioblastoma in rats (GrahamGurysh et al., 2018).

In 2014, a matrix consisting of cytarabine-loaded phospholipid vesicles was described by Qi et al., which composed of a gel-like semi-solid dispersion of phospholipids. The peculiarity of this matrix is the high resistance to autoclaving, which meets one of the main requirements of hydrogels for the use in the treatment of brain cancers: sterility. The phospholipid vesicles implant in animal models was shown to release a drug (cytarabine) for at least 28 days with a good biodistribution profile and penetration depth of a drug after intracerebral injection. In addition, no implant rejection was observed (Qi et al., 2012, 2014).

An excellent example of a hydrogel implant based on lipid nanocapsules was described in 2015 by Aparicio-Blanco and Torres-Suárez (Aparicio-Blanco and Torres-Suárez, 2015). This matrix is uniquely formed byx lipid nanocapsules (LNC) in combination with GemC12 (Gemcitabine); besides that gel does not contain any polymeric components. The formation of this hydrogel occurs due to location of GemC12 at the interface of the oil-water LNC, which ensures the formation of crosslinking $\mathrm{H}$-bonds between the drug fragments and immobilization of the aqueous phase. Compared to previously mentioned varieties of hydrogels, the advantage of this system is in the structure simplicity as the gel decomposition results in release of only GemC12-LNC, because it contains no other components (synthetic or natural polymers, gelling agents, external irritants), which reduces the risk of side effects. In vivo studies showed that this system showed is well-tolerated in the brain of mice, both in short ( 1 week) and long (2 and 6 months) experiments (Bastiancich et al., 2016b, 2017). The degradation of the hydrogel corresponded to the sustained release of the drug, which lasted over 1 month. Intratumoral administration of this hydrogel in a human orthotopic xenograft model of a person with GBM showed a significant increase in survival compared with the control (Bastiancich et al., 2018).

The melittin-containing peptide hydrogel Melittin-RADA 32 Indocyanine green described by Jin et al. in 2017 also raised significant interest. It was constructed from the RADA32melittin fusion peptide in the presence of $0.9 \% \mathrm{NaCl}$ and encapsulated in the hydrogel, with indocyanine green added. In vivo experiments with this hydrogel showed excellent results in visualizing residual tumor cells. Three hours after the hydrogel administration, Magnetic resonance imaging analysis showed 
significant signals in tumors, thus it is possible to distinguish diffused tumor cells left after surgery. Furthermore, this hydrogel is able to release the drug in required doses and protect the implant itself from rapid decomposition or elimination. However, melittin has non-specific cytotoxicity and hemolytic activity, which limits its therapeutic use (Jin et al., 2017).

The most unusual implant is a chitosan-based hydrogel capable of releasing temozolomide while including radioactive iodine isotopes. This implant is applied for local complex therapy providing chemo- and radiation therapy simultaneously. At the time of writing, the first tests of this hydrogel were carried out, but there was no extensive data. However, the release of drug was negligible after 42 days, whereas the TMZ was completely released over the first $48 \mathrm{~h}$ (Puente et al., 2018). Nevertheless, the authors believe that this trend is promising due to the fact that post-operative systemic therapy has a complex effect, and therefore local therapy should be more convenient. However, at the moment there is no data on the survival of the model objects as well as the possible drawbacks of this hydrogel.

\section{CONCLUSIONS}

In recent years, targeted delivery systems have been developed for various therapeutic agents, such as chemotherapy drugs, stem or committed cells, which all can be used in the treatment of gliomas and provide a substantial improvement in its prognosis (Nakamizo et al., 2005; Lee et al., 2011; Hu et al., 2013). Carriers are materials of different nature, which to a greater or lesser extent have such advantages as custom mechanical properties, good biocompatibility, conventional way of matrix introduction (during operation), as well as the ability to deliver various biologically active substances and drugs.

In the treatment of brain tumors hydrogels can be employed for the effective delivery of chemotherapeutic agents while do not require highly invasive procedures. They proved to be unique platforms for local and systemic methods of drug delivery due to their high biocompatibility, biodegradability, and the presence of active functional groups. Combination of nanoparticles and hydrogels bringing up a possibility of creating material capable of crossing the $\mathrm{BBB}$ and effectively detecting and destroying tumor cells without harming healthy brain cells.

Hydrogels can also be used for targeted delivery to tumor cells and the delivery of highly toxic drugs. For example, when encapsulating immunostimulating drugs in a hydrogel, it becomes possible to deliver them to the resection cavity without the need to cross the $\mathrm{BBB}$ and with the possibility of their gradual release. It is also possible to reduce the total damage to the patient's body by encapsulating toxic drugs, such as platinum nanoparticles. However, the best results can be achieved by encapsulating these drugs in modified nanoparticles, which will be placed in the resection cavity in the hydrogel. This approach will minimize the disadvantages of systemic delivery of these drugs, almost completely reduce the toxic harm to the patient's body, but at the same time increase the therapeutic effectiveness of these drugs (Xiao et al., 2018; Feng et al., 2019; Yu et al., 2019).
Synthetic polymers are widely used as components of systems for drug delivery due to their well-known chemical and structural characteristics, as well as the ability to control and easily adjust the physico-chemical properties of the matrix. However, synthetic materials do not display biological activity and lack the ability to fully imitate the native extracellular matrix even after modification by adhesive sites. Unfortunately, the degradation of synthetic material can lead to release of cytotoxic or inflammatory small molecules (Stoppel et al., 2015).

Recently, growing interest has been raised to the field of matrices consisting partially or entirely of natural materials, due to their ability to influence cell proliferation at the edges of the resection cavity. This effect can reduce the risk of tumor recurrence from residual cells that were omitted during surgery (Huynh et al., 2009).

Natural materials are derived from substances of plant or animal origin. After purification and preparation for in vivo use they usually do not cause an undesirable or unexpected immune response proposing a source for biocompatible and often biologically active matrix capable of integration with the surrounding native tissue (Lee et al., 2014). In addition, the products of natural material degradation are usually more biologically compatible, metabolically acceptable, and less toxic than synthetic analogs. Disadvantages of biomaterials from natural origin are their chemical heterogeneity in combination with high dispersion that, as a result, cause variability of structure, mechanical properties, and degradation rates between different batches of the same material. Despite variability, biopolymer matrix materials of natural origin have been successfully applied clinically for the restoration of soft (skin and muscles) (Später et al., 2018) and hard tissues (bone) (Giuliani et al., 2014).

A lot of studies reviewed in this paper reported significantly increased efficiency of tumor growth inhibition as a result of utilizing matrix materials after resection, as well as synergistic effect that can be achieved through a combination of several chemical agents or therapeutic approaches. To solve all vital problems arising during GBM treatment (precise tumor localization, eliminating delays in the course of treatment, prevention of relapse), it is necessary to further study multifunctional implants, since they are capable of passing over the maximum number of obstacles with minimal intervention in the human brain.

Thus, promising hydrogel-based drug co-delivery systems will make a significant contribution to cancer treatment and human health.

\section{AUTHOR CONTRIBUTIONS}

$\mathrm{AB}, \mathrm{ST}, \mathrm{NS}, \mathrm{MG}, \mathrm{GM}, \mathrm{VG}, \mathrm{AK}$, and VK wrote the manuscript. $\mathrm{AB}, \mathrm{GM}, \mathrm{ST}$, and NS drew the figures. All authors approved the final manuscript.

\section{FUNDING}

This work was supported by the Ministry of Science and Higher Education of the Russian Federation (project \# 6.7997.2017/6u). 


\section{REFERENCES}

Agudelo-Garcia, P. A., De Jesus, J. K., Williams, S. P., Nowicki, M. O., Chiocca, E. A., Liyanarachchi, S., et al. (2011). Glioma cell migration on three-dimensional nanofiber scaffolds is regulated by substrate topography and abolished by inhibition of Stat3 signaling. Neoplasia 13, 831-840. doi: 10.1593/neo.11612

Akbar, U., Jones, T., Winestone, J., Michael, M., Shukla, A., Sun, Y., et al. (2009). Delivery of temozolomide to the tumor bed via biodegradable gel matrices in a novel model of intracranial glioma with resection. J. Neurooncol. 94, 2031-2212. doi: 10.1007/s11060-009-9857-9

Akiyama, Y., Jung, S., Salhia, B., Lee, S., Hubbard, S., Taylor, M., et al. (2001). Hyaluronate receptors mediating glioma cell migration and proliferation. $J$. Neurooncol. 53, 115-127. doi: 10.1023/A:1012297132047

Albanese, A., Tang, P. S., and Chan, W. C. (2012). The effect of nanoparticle size, shape, and surface chemistry on biological systems. Annu. Rev. Biomed. Eng. 14, 1-16. doi: 10.1146/annurev-bioeng-071811-150124

Alemany-Ribes, M., and Semino, C. E. (2014). Bioengineering 3D environments for cancer models. Adv. Drug Deliv. Rev. 79-80, 40-49. doi: 10.1016/j.addr.2014.06.004

Álvarez, Z., Castaño, O., Castells, A. A., Mateos-Timoneda, M. A., Planell, J. A., Engel, E., et al. (2014). Neurogenesis and vascularization of the damaged brain using a lactate-releasing biomimetic scaffold. Biomaterials 35, 4769-4781. doi: 10.1016/j.biomaterials.2014.02.051

Ansorena, E., De Berdt, P., Ucakar, B., Simón-Yarza, T., Jacobs, D., Schakman, O., et al. (2013). Injectable alginate hydrogel loaded with GDNF promotes functional recovery in a hemisection model of spinal cord injury. Int. J. Pharm. 455, 148-158. doi: 10.1016/j.jijpharm.2013.07.045

Aparicio-Blanco, J., and Torres-Suárez, A. I. (2015). Glioblastoma multiforme and lipid nanocapsules: a review. J. Biomed. Nanotechnol. 11, 1283-1311. doi: $10.1166 /$ jbn.2015.2084

Arai, T., Benny, O., Joki, T., Menon, L. G., Machluf, M., Abe, T., et al. (2010). Novel local drug delivery system using thermoreversible gel in combination with polymeric microspheres or liposomes. Anticancer Res. 30, 1057-1064.

Armstrong, L., Hughes, O., Yung, S., Hyslop, L., Stewart, R., Wappler, I., et al. (2006). The role of $\mathrm{PI}_{3} \mathrm{~K} / \mathrm{AKT}, \mathrm{MAPK} / \mathrm{ERK}$ and $\mathrm{NF \kappa} \beta$ signalling in the maintenance of human embryonic stem cell pluripotency and viability highlighted by transcriptional profiling and functional analysis. Hum. Mol. Genet. 15, 1894-1913. doi: 10.1093/hmg/ddl112

Autier, L., Clavreul, A., Cacicedo, M. L., Franconi, F., Sindji, L., Rousseau, A., et al. (2019). A new glioblastoma cell trap for implantation after surgical resection. Acta Biomater. 84, 268-279. doi: 10.1016/j.actbio.2018.11.027

Bagó, J. R., Pegna, G. J., Okolie, O., Mohiti-Asli, M., Loboa, E. G., and Hingtgen, S. D. (2016). Electrospun nanofibrous scaffolds increase the efficacy of stem cellmediated therapy of surgically resected glioblastoma. Biomaterials 90, 116-125. doi: 10.1016/j.biomaterials.2016.03.008

Baskaran, S., Mayrhofer, M., Kultima, H. G., Bergström, T., Elfineh, L., Cavelier, L., et al. (2018). Primary glioblastoma cells for precision medicine: a quantitative portrait of genomic (in)stability during the first 30 passages. Neurooncology 20 , 1080-1091. doi: 10.1093/neuonc/noy024

Bastiancich, C., Bianco, J., Vanvarenberg, K., Ucakar, B., Joudiou, N., Gallez, B., et al. (2017). Injectable nanomedicine hydrogel for local chemotherapy of glioblastoma after surgical resection. J. Control. Release 264, 45-54. doi: 10.1016/j.jconrel.2017.08.019

Bastiancich, C., Danhier, P., Préat, V., and Danhier, F. (2016a). Anticancer drug-loaded hydrogels as drug delivery systems for the local treatment of glioblastoma. J. Control Release 243, 29-42. doi: 10.1016/j.jconrel.2016.09.034

Bastiancich, C., Lemaire, L., Bianco, J., Franconi, F., Danhier, F., Préat, V., et al. (2018). Evaluation of lauroyl-gemcitabine-loaded hydrogel efficacy in glioblastoma rat models. Nanomedicine. 13, 1999-2013. doi: 10.2217/nnm-2018-0057

Bastiancich, C., Vanvarenberg, K., Ucakar, B., Pitorre, M., Bastiat, G., Lagarce, F., et al. (2016b). Lauroyl-gemcitabine-loaded lipid nanocapsule hydrogel for the treatment of glioblastoma. J. Control Release 225, 283-293. doi: 10.1016/j.jconrel.2016.01.054

Bellail, A. C., Hunter, S. B., Brat, D. J., Tan, C., and Van Meir, E. G. (2004). Microregional extracellular matrix heterogeneity in brain modulates glioma cell invasion. Int. J. Biochem. Cell Biol. 36, 1046-1069. doi: 10.1016/j.biocel.2004.01.013
Bennet, D., and Kim, S. (2014). Polymer Nanoparticles for Smart Drug Delivery. London: Intechopen.

Bilozur, M. E., and Hay, E. D. (1988). Neural crest migration in 3D extracellular matrix utilizes laminin, fibronectin, or collagen. Dev. Biol. 125, 19-33. doi: 10.1016/0012-1606, 90055-3

Bjugstad, K. B., Lampe, K., Kern, D. S., and Mahoney, M. (2010). Biocompatibility of poly(ethylene glycol)-based hydrogels in the brain: an analysis of the glial response across space and time. J. Biomed. Mater. Res. Part A 95, 79-91. doi: $10.1002 /$ jbm.a.32809

Bouterfa, H., Janka, M., Meese, E., Kerkau, S., Roosen, K., and Tonn, J. C. (1997). Effect of changes in the CD44 gene on tumour cell invasion in gliomas. Neuropathol. Appl. Neurobiol. 23, 373-379. doi: 10.1111/j.1365-2990.1997.tb01311.x

Chai, Z., Hu, X., Wei, X., Zhan, C., Lu, L., Jiang, K., et al. (2017). A facile approach to functionalizing cell membrane-coated nanoparticles with neurotoxin-derived peptide for brain-targeted drug delivery. J. Control Release 264, 102-111. doi: 10.1016/j.jconrel.2017. 08.027

Champion, J. A., and Mitragotri, S. (2006). Role of target geometry in phagocytosis. Proc. Natl. Acad. Sci. U.S.A. 103, 4930-4934. doi: 10.1073/pnas.0600997103

Chen, J. E., Pedron, S., and Harley, B. A. C. (2017). The combined influence of hydrogel stiffness and matrix-bound hyaluronic acid content on glioblastoma invasion. Macromol. Biosci. 17:1700018. doi: 10.1002/mabi.201700018

Chiquet-Ehrismann, R., Orend, G., Chiquet, M., Tucker, R. P., and Midwood, K. S. (2014). Tenascins in stem cell niches. Matrix Biol. 37, 112-123. doi: 10.1016/j.matbio.2014.01.007

Cook, D. J., Nguyen, C., Chun, H. N., Llorente, I. L., Chiu, A. S., Machnicki, M., et al. (2017). Hydrogel-delivered brain-derived neurotrophic factor promotes tissue repair and recovery after stroke. J. Cereb. Blood Flow Metab. 37, 1030-1045. doi: 10.1177/0271678X16649964

Cuddapah, V. A., Robel, S., Watkins, S., and Sontheimer, H. (2014). A neurocentric perspective on glioma invasion. Nat. Rev. Neurosci. 15, 455-465. doi: $10.1038 / \mathrm{nrn} 3765$

De la Garza-Ramos, R., Kerezoudis, P., Tamargo, R. J., Brem, H., Huang, J., and Bydon, M. (2016). Surgical complications following malignant brain tumor surgery: an analysis of 2002-2011 data. Clin. Neurol. Neurosurg. 140, 6-10. doi: 10.1016/j.clineuro.2015.11.005

Delpech, B., Maingonnat, C., Girard, N., Chauzy, C., Maunoury, R., Olivier, A., et al. (1993). Hyaluronan and hyaluronectin in the extracellular matrix of human brain tumour stroma. Eur. J. Cancer 29, 1012-1017. doi: 10.1016/S0959-8049, 80214-X

Dhandapani, M., Gupta, S., Mohanty, M., Gupta, S. K., and Dhandapani, S. (2016). Trends in cognitive dysfunction following surgery for intracranial tumors. Surg. Neurol. Int. 7, S190-S195. doi: 10.4103/2152-7806.179229

Dwyer, C. A., Bi, W. L., Viapiano, M. S., and Matthews, R. T. (2014). Brevican knockdown reduces late-stage glioma tumor aggressiveness. J. Neurooncol. 120, 63-72. doi: 10.1007/s11060-014-1541-z

Erickson, A. E., Lan Levengood, S. K., Sun, J., Chang, F. C., and Zhang, M. (2018). Fabrication and characterization of chitosan-hyaluronic acid scaffolds with varying stiffness for glioblastoma cell culture. Adv. Healthc. Mater. 7:e1800295. doi: $10.1002 / \mathrm{adhm} .201800295$

Fangusaro, J. (2012). Pediatric high grade glioma: a review and update on tumor clinical characteristics and biology. Front Oncol. 2:105. doi: $10.3389 /$ fonc. 2012.00105

Feng, X., Xu, W., Li, Z., Song, W., Ding, J., and Chen, X. (2019). Immunomodulatory nanosystems. Adv. Sci. 6:1900101. doi: 10.1002/advs.201900101

Fon, D., Zhou, K., Ercole, F., Fehr, F., Marchesan, S., Minter, M. R., et al. (2014). Nanofibrous scaffolds releasing a small molecule BDNF-mimetic for the redirection of endogenous neuroblast migration in the brain. Biomaterials 35 , 2692-2712. doi: 10.1016/j.biomaterials.2013.12.016

Fourniols, T., Randolph, L. D., Staub, A., Vanvarenberg, K., Leprince, J. G., Préat, V., et al. (2015). Temozolomide-loaded photopolymerizable PEG-DMA-based hydrogel for the treatment of glioblastoma. J. Control. Release 210, 95-104. doi: 10.1016/j.jconrel.2015.05.272

Furnari, F. B., Fenton, T., Bachoo, R. M., Mukasa, A., Stommel, J. M., Stegh, A., et al. (2007). Malignant astrocytic glioma: genetics, biology, and paths to treatment. Genes Dev. 21, 2683-2710. doi: 10.1101/gad.1596707 
Furtado, D., Björnmalm, M., Ayton, S., Bush, A. I., Kempe, K., and Caruso, F. (2018). Overcoming the blood-brain barrier: the role of nanomaterials in treating neurological diseases. Adv. Mater. Weinheim. 30:e1801362. doi: 10.1002/adma.201801362

Ghasemi-Mobarakeh, L., Prabhakaran, M. P., Morshed, M., Nasr-Esfahani, M. H., and Ramakrishna, S. (2008). Electrospun poly(epsilon-caprolactone)/gelatin nanofibrous scaffolds for nerve tissue engineering. Biomaterials 29, 4532-4539. doi: 10.1016/j.biomaterials.2008.08.007

Ghuman, H., Mauney, C., Donnelly, J., Massensini, A. R., Badylak, S. F., and Modo, M. (2018). Biodegradation of ECM hydrogel promotes endogenous brain tissue restoration in a rat model of stroke. Acta Biomater. 80, 66-84. doi: 10.1016/j.actbio.2018.09.020

Giuliani, A., Manescu, A., Larsson, E., Tromba, G., Luongo, G., Piattelli, A., et al. (2014). In vivo regenerative properties of coralline-derived (biocoral) scaffold grafts in human maxillary defects: demonstrative and comparative study with Beta-tricalcium phosphate and biphasic calcium phosphate by synchrotron radiation x-ray microtomography. Clin. Implant Dent. Relat. Res. 16, 736-750. doi: $10.1111 /$ cid.12039

Gordon, V. D., Valentine, M. T., Gardel, M. L., Andor-Ardó, D., Dennison, S., Bogdanov, A. A., et al. (2003). Measuring the mechanical stress induced by an expanding multicellular tumor system: a case study. Exp. Cell Res. 289, 58-66. doi: 10.1016/s0014-4827(03)00256-8

Graham-Gurysh, E., Moore, K. M., Satterlee, A. B., Sheets, K. T., Lin, F. C., Bachelder, E. M., et al. (2018). Sustained delivery of doxorubicin via acetalated dextran scaffold prevents glioblastoma recurrence after surgical resection. Mol. Pharm. 15, 1309-1318. doi: 10.1021/acs.molpharmaceut.7b01114

Grossman, S. A., Reinhard, C., Colvin, O. M., Chasin, M., Brundrett, R., Tamargo, R. J., et al. (1992). The intracerebral distribution of BCNU delivered by surgically implanted biodegradable polymers. J. Neurosurg. 76, 640-647. doi: $10.3171 /$ jns. 1992.76 .4 .0640

Gulaia, V., Kumeiko, V., Shved, N., Cicinskas, E., Rybtsov, S., Ruzov, A., et al. (2018). Molecular mechanisms governing the stem cell's fate in brain cancer: factors of stemness and quiescence. Front. Cell Neurosci. 12:388. doi: 10.3389 /fncel.2018.00388

Hay, E. D. (1993). Extracellular matrix alters epithelial differentiation. Curr. Opin. Cell Biol. 5, 1029-1035. doi: 10.1016/0955-0674, 90088-8

Hrapko, M., van Dommelen, J. A., Peters, G. W., and Wismans, J. S. (2008). The influence of test conditions on characterization of the mechanical properties of brain tissue. J. Biomech. Eng. 130:031003. doi: 10.1115/1.2907746

Hu, Q., Gao, X., Gu, G., Kang, T., Tu, Y., Liu, Z., et al. (2013). Glioma therapy using tumor homing and penetrating peptide-functionalized PEGPLA nanoparticles loaded with paclitaxel. Biomaterials 34, 5640-5650. doi: 10.1016/j.biomaterials.2013.04.025

Huynh, N. T., Passirani, C., Saulnier, P., and Benoit, J. P. (2009). Lipid nanocapsules: a new platform for nanomedicine. Int. J. Pharm. 379, 201-209. doi: 10.1016/j.ijpharm.2009.04.026

Imbeault, S., Gauvin, L. G., Toeg, H. D., Pettit, A., Sorbara, C. D., Migahed, L., et al. (2009). The extracellular matrix controls gap junction protein expression and function in postnatal hippocampal neural progenitor cells. BMC Neurosci. 10:13. doi: 10.1186/1471-2202-10-13

Isa, I. L., Srivastava, A., Tiernan, D., Owens, P., Rooney, P., Dockery, P., et al. (2015). Hyaluronic acid based hydrogels attenuate inflammatory receptors and neurotrophins in interleukin-1 $\beta$ induced inflammation model of nucleus pulposus cells. Biomacromolecules 16, 1714-1725. doi: 10.1021/acs.biomac.5b00168

Jain, A., Kim, Y. T., McKeon, R. J., and Bellamkonda, R. V. (2006). In situ gelling hydrogels for conformal repair of spinal cord defects, and local delivery of BDNF after spinal cord injury. Biomaterials 27, 497-504. doi: 10.1016/j.biomaterials.2005.07.008

Jain, S., Mishra, V., Singh, P., Dubey, P. K., Saraf, D. K., and Vyas, S. P. (2003). RGD-anchored magnetic liposomes for monocytes/neutrophils-mediated brain targeting. Int. J. Pharm. 261, 43-55. doi: 10.1016/s0378-5173(03) 00269-2

Jaworski, S., Sawosz, E., Kutwin, M., Wierzbicki, M., Hinzmann, M., Grodzik, M., et al. (2015). In vitro and in vivo effects of graphene oxide and reduced graphene oxide on glioblastoma. Int. J. Nanomedicine 10, 1585-1596. doi: 10.2147/IJN.S77591

Jia, W., Jiang, X., Liu, W., Wang, L., Zhu, B., Zhu, H., et al. (2018). Effects of three-dimensional collagen scaffolds on the expression profiles and biological functions of glioma cells. Int. J. Oncol. 52, 1787-1800 doi: 10.3892/ijo.2018.4330

Jiang, L., Zhou, Q., Mu, K., Xie, H., Zhu, Y., Zhu, W., et al. (2013). pH/temperature sensitive magnetic nanogels conjugated with Cy5.5-labled lactoferrin for MR and fluorescence imaging of glioma in rats. Biomaterials 34, 7418-7428. doi: 10.1016/j.biomaterials.2013.05.078

Jin, H., Zhao, G., Hu, J., Ren, Q., Yang, K., Wan, C., et al. (2017). Melittin-containing hybrid peptide hydrogels for enhanced photothermal therapy of glioblastoma. ACS Appl. Mater. Interfaces 9, 25755-25766. doi: 10.1021/acsami.7b06431

Kaufman, L. J., Brangwynne, C. P., Kasza, K. E., Filippidi, E., Gordon, V. D. Deisboeck, T. S., et al. (2005). Glioma expansion in collagen I matrices: analyzing collagen concentration-dependent growth and motility patterns. Biophys. J. 89, 635-650. doi: 10.1529/biophysj.105.061994

Kearns, S. M., Laywell, E. D., Kukekov, V. K., and Steindler, D. A. (2003). Extracellular matrix effects on neurosphere cell motility. Exp. Neurol. 182, 240-244. doi: 10.1016/S0014-4886, 00124-9

Kerever, A., Schnack, J., Vellinga, D., Ichikawa, N., Moon, C., ArikawaHirasawa, E., et al. (2007). Novel extracellular matrix structures in the neural stem cell niche capture the neurogenic factor fibroblast growth factor 2 from the extracellular milieu. Stem Cells 25, 2146-2157. doi: 10.1634/stemcells.2007-0082

Kievit, F. M., Cooper, A., Jana, S., Leung, M. C., Wang, K., Edmondson, D., et al. (2013). Aligned chitosan-polycaprolactone polyblend nanofibers promote the migration of glioblastoma cells. Adv. Healthc. Mater. 2, 1651-1659. doi: 10.1002/adhm.201300092

Kievit, F. M., Florczyk, S. J., Leung, M. C., Wang, K., Wu, J. D., Silber, J. R., et al. (2014). Proliferation and enrichment of CD133(+) glioblastoma cancer stem cells on 3D chitosan-alginate scaffolds. Biomaterials 35, 9137-9143. doi: 10.1016/j.biomaterials.2014.07.037

Kim, C. F., Jackson, E. L., Woolfenden, A. E., Lawrence, S., Babar, I., Vogel, S., et al. (2005). Identification of bronchioalveolar stem cells in normal lung and lung cancer. Cell 121, 823-835. doi: 10.1016/j.cell.2005.03.032

Kim, K. K., and Pack, D. W. (2006). "Microspheres for drug delivery," in BioMEMS and Biomedical Nanotechnology: Volume I Biological and Biomedical Nanotechnology, eds M. Ferrari, A. P. Lee, and L. J. Lee (Boston, MA: Springer US), 19-50.

Klein, E. A., Yin, L., Kothapalli, D., Castagnino, P., Byfield, F. J., Xu, T., et al. (2009). Cell-cycle control by physiological matrix elasticity and in vivo tissue stiffening. Curr. Biol. 19, 1511-1518. doi: 10.1016/j.cub.2009.07.069

Knott, J. C., Mahesparan, R., Garcia-Cabrera, I., Bølge Tysnes, B., Edvardsen, K., Ness, G. O., et al. (1998). Stimulation of extracellular matrix components in the normal brain by invading glioma cells. Int. J. Cancer 75, 864-872.

Kondo, T., Setoguchi, T., and Taga, T. (2004). Persistence of a small subpopulation of cancer stem-like cells in the C6 glioma cell line. Proc. Natl. Acad. Sci. U.S.A. 101, 781-786. doi: 10.1073/pnas.0307618100

Konishi, Y., Muragaki, Y., Iseki, H., Mitsuhashi, N., and Okada, Y. (2012). Patterns of intracranial glioblastoma recurrence after aggressive surgical resection and adjuvant management: retrospective analysis of 43 cases. Neurol. Med. Chir. (Tokyo) 52, 577-586. doi: 10.2176/nmc.52.577

Koochekpour, S., Pilkington, G. J., and Merzak, A. (1995). Hyaluronic acid/CD $44 \mathrm{H}$ interaction induces cell detachment and stimulates migration and invasion of human glioma cells in vitro. Int. J. Cancer 63, 450-454. doi: $10.1002 /$ ijc. 2910630325

Kunert, P., Smolarek, B., and Marchel, A. (2011). Facial nerve damage following surgery for cerebellopontine angle tumours. Prevention and comprehensive treatment. Neurol. Neurochir. Pol. 45, 480-488. doi: 10.1016/S0028-3843, 60317-0

Lathia, J. D., Li, M., Hall, P. E., Gallagher, J., Hale, J. S., Wu, Q., et al. (2012). Laminin alpha 2 enables glioblastoma stem cell growth. Ann. Neurol. 72, 766-778. doi: 10.1002/ana.23674

Lathia, J. D., Patton, B., Eckley, D. M., Magnus, T., Mughal, M. R., Sasaki, T., et al. (2007). Patterns of laminins and integrins in the embryonic ventricular zone of the CNS. J. Comp. Neurol. 505, 630-643. doi: 10.1002/cne.21520

Lau, L. W., Cua, R., Keough, M. B., Haylock-Jacobs, S., and Yong, V. W. (2013). Pathophysiology of the brain extracellular matrix: a new target for remyelination. Nat. Rev. Neurosci. 14, 722-729. doi: 10.1038/nrn3550

Lee, E. J., Kasper, F. K., and Mikos, A. G. (2014). Biomaterials for tissue engineering. Ann. Biomed. Eng. 42, 323-337. doi: 10.1007/s10439-013-0859-6 
Lee, E. X., Lam, D. H., Wu, C., Yang, J., Tham, C. K., Ng, W. H., et al. (2011). Glioma gene therapy using induced pluripotent stem cell derived neural stem cells. Mol. Pharm. 8, 1515-1524. doi: 10.1021/mp200127u

Lee, K. Y., and Mooney, D. J. (2012). Alginate: properties and biomedical applications. Prog. Polym. Sci. 37, 106-126. doi: 10.1016/j.progpolymsci.2011.06.003

Liu, D., Pearlman, E., Diaconu, E., Guo, K., Mori, H., Haqqi, T., et al. (1996). Expression of hyaluronidase by tumor cells induces angiogenesis in vivo. Proc. Natl. Acad. Sci. U.S.A. 93, 7832-7837. doi: 10.1073/pnas.93.15.7832

Mahmoudi, K., Bouras, A., Bozec, D., Ivkov, R., and Hadjipanayis, C. (2018). Magnetic hyperthermia therapy for the treatment of glioblastoma: a review of the therapy's history, efficacy and application in humans. Int. J. Hyperthermia 34, 1316-1328. doi: 10.1080/02656736.2018.1430867

Maier-Hauff, K., Rothe, R., Scholz, R., Gneveckow, U., Wust, P., Thiesen, B., et al. (2007). Intracranial thermotherapy using magnetic nanoparticles combined with external beam radiotherapy: results of a feasibility study on patients with glioblastoma multiforme. J. Neurooncol. 81, 53-60. doi: 10.1007/s11060-006-9195-0

Malinovskaya, Y., Melnikov, P., Baklaushev, V., Gabashvili, A., Osipova, N., Mantrov, S., et al. (2017). Delivery of doxorubicin-loaded PLGA nanoparticles into U87 human glioblastoma cells. Int. J. Pharm. 524, 77-90. doi: 10.1016/j.ijpharm.2017.03.049

Mallick, S., Benson, R., Hakim, A., and Rath, G. K. (2016). Management of glioblastoma after recurrence: a changing paradigm. J. Egypt. Natl. Canc. Inst. 28, 199-210. doi: 10.1016/j.jnci.2016.07.001

Martínez-Ramos, C., Vallés-Lluch, A., Verdugo, J. M., Ribelles, J. L., Barcia Albacar, J. A., Orts, A. B., et al. (2012). Channeled scaffolds implanted in adult rat brain. J. Biomed. Mater. Res. A 100, 3276-3286. doi: 10.1002/jbm.a.34273

Mecham, R. P. (2012). Overview of extracellular matrix. Curr. Protoc. Cell Biol. Chapter 10:11. doi: 10.1002/0471143030.cb1001s57

Mercier, F. (2016). Fractones: extracellular matrix niche controlling stem cell fate and growth factor activity in the brain in health and disease. Cell. Mol. Life Sci. 73, 4661-4674. doi: 10.1007/s00018-016-2314-y

Mikhailova, V., Gulaia, V., Tiasto, V., Rybtsov, S., Yatsunskaya, M., and Kagansky, A. (2018). Towards an advanced cell-based in vitro glioma model system. AIMS Genet. 5, 91-112. doi: 10.3934/genet.2018.2.91

Miroshnikova, Y. A., Mouw, J. K., Barnes, J. M., Pickup, M. W., Lakins, J. N., Kim, Y., et al. (2016). Tissue mechanics promote IDH1-dependent HIF1alphatenascin C feedback to regulate glioblastoma aggression. Nat. Cell Biol. 18, 1336-1345. doi: 10.1038/ncb3429

Morshed, R. A., Cheng, Y., Auffinger, B., Wegscheid, M. L., and Lesniak, M. S. (2013). The potential of polymeric micelles in the context of glioblastoma therapy. Front. Pharmacol. 4:157. doi: 10.3389/fphar.2013.00157

Mouw, J. K., Ou, G., and Weaver, V. M. (2014). Extracellular matrix assembly: a multiscale deconstruction. Nat. Rev. Mol. Cell Biol. 15, 771-785. doi: $10.1038 / \mathrm{nrm} 3902$

Müller, R. H., Radtke, M., and Wissing, S. A. (2002). Solid lipid nanoparticles (SLN) and nanostructured lipid carriers (NLC) in cosmetic and dermatological preparations. Adv. Drug Deliv. Rev. 54, S131-S155. doi: 10.1016/S0169-409X(02)00118-7

Nakamizo, A., Marini, F., Amano, T., Khan, A., Studeny, M., Gumin, J., et al. (2005). Human bone marrow-derived mesenchymal stem cells in the treatment of gliomas. Cancer Res. 65, 3307-3318. doi: 10.1158/0008-5472.CAN-04-1874

Nam, L., Coll, C., Erthal, L. C. S., de la Torre, C., Serrano, D., Martínez-Máñez, R., et al. (2018). Drug delivery nanosystems for the localized treatment of glioblastoma multiforme. Materials (Basel). 11:e779. doi: 10.3390/ma11050779

Ng, J. C. H., See, A. A. Q., Ang, T. Y., Tan, L. Y. R., Ang, B. T., and King, N. K. K. (2019). Effects of surgery on neurocognitive function in patients with glioma: a meta-analysis of immediate post-operative and long-term follow-up neurocognitive outcomes. J. Neurooncol. 141, 167-182. doi: 10.1007/s11060-018-03023-9

Nicholson, C., and Syková, E. (1998). Extracellular space structure revealed by diffusion analysis. Trends Neurosci. 21, 207-215. doi: 10.1016/S0166-223601261-2

Nih, L. R., Gojgini, S., Carmichael, S. T., and Segura, T. (2018). Dual-function injectable angiogenic biomaterial for the repair of brain tissue following stroke. Nat. Mater. 17, 642-651. doi: 10.1038/s41563-018-0083-8

Novak, U., and Kaye, A. H. (2000). Extracellular matrix and the brain: components and function. J. Clin. Neurosci. 7, 280-290. doi: 10.1054/jocn.1999.0212
Novak, U., Stylli, S. S., Kaye, A. H., and Lepperdinger, G. (1999). Hyaluronidase-2 overexpression accelerates intracerebral but not subcutaneous tumor formation of murine astrocytoma cells. Cancer Res. 59, 6246-6250.

Nyagilo, J., Piccirillo, S., Sun, Y., Bui, L., Regmi, N., Wright, J. L., et al. (2017). Abstract A54: extracellular matrix geometry and 3D spatial confinement trigger diverse mechanisms of primary human glioblastoma cell migration. Cancer Res. 77:A54. doi: 10.1158/1538-7445.EPSO16-A54

Nyga, A., Cheema, U., and Loizidou, M. (2011). 3D tumour models: novel in vitro approaches to cancer studies. J. Cell Commun. Signal 5, 239-248. doi: 10.1007/s12079-011-0132-4

Ostrom, Q. T., Bauchet, L., Davis, F. G., Deltour, I., Fisher, J. L., Langer, C. E., et al. (2014). The epidemiology of glioma in adults: a "state of the science" review. Neuro-oncol. 16, 896-913. doi: 10.1093/neuonc/nou087

Ozeki, T., Kaneko, D., Hashizawa, K., Imai, Y., Tagami, T., and Okada, H. (2012). Combination therapy of surgical tumor resection with implantation of a hydrogel containing camptothecin-loaded poly(lactic-co-glycolic acid) microspheres in a C6 rat glioma model. Biol. Pharm. Bull. 35, 545-550. doi: 10.1248/bpb.35.545

Paul, C. D., Mistriotis, P., and Konstantopoulos, K. (2017). Cancer cell motility: lessons from migration in confined spaces. Nat. Rev. Cancer 17, 131-140. doi: $10.1038 / \mathrm{nrc} .2016 .123$

Pawar, K., Prang, P., Müller, R., Caioni, M., Bogdahn, U., Kunz, W., et al. (2015). Intrinsic and extrinsic determinants of central nervous system axon outgrowth into alginate-based anisotropic hydrogels. Acta Biomater. 27, 131-139. doi: 10.1016/j.actbio.2015.08.032

Pedron, S., Becka, E., and Harley, B. A. (2013). Regulation of glioma cell phenotype in 3D matrices by hyaluronic acid. Biomaterials 34, 7408-7417. doi: 10.1016/j.biomaterials.2013.06.024

Pedron, S., Hanselman, J. S., Schroeder, M. A., Sarkaria, J. N., and Harley, B. A. C. (2017). Extracellular hyaluronic acid influences the efficacy of EGFR tyrosine kinase inhibitors in a biomaterial model of glioblastoma. Adv. Healthc. Mater. 6:1700529 doi: 10.1002/adhm.201700529

Pinel, S., Thomas, N., Boura, C., and Barberi-Heyob, M. (2019). Approaches to physical stimulation of metallic nanoparticles for glioblastoma treatment. $A d v$. Drug Deliv. Rev. 138, 344-357. doi: 10.1016/j.addr.2018.10.013

Pinto, L. W., Araújo, M. B., Vettore, A. L., Wernersbach, L., Leite, A. C., Chimelli, L. M., et al. (2008). Glioblastomas: correlation between oligodendroglial components, genetic abnormalities, and prognosis. Virchows Arch. 452, 481-490. doi: 10.1007/s00428-007-0562-9

Plopper, G. (2015). "The extracellular matrix and cell adhesion," in Cells, eds G. Plopper and E. Sikorski (Burlington, MA: Jones and Bartlett), 831-889.

Pogoda, K., Chin, L., Georges, P. C., Byfield, F. J., Bucki, R., Kim, R., et al. (2014). Compression stiffening of brain and its effect on mechanosensing by glioma cells. New J. Phys. 16:075002. doi: 10.1088/1367-2630/16/7/075002

Puente, P., Fettig, N., Luderer, M. J., Jin, A., Shah, S., Muz, B., et al. (2018). Injectable hydrogels for localized chemotherapy and radiotherapy in brain tumors. J. Pharm. Sci. 107, 922-933. doi: 10.1016/j.xphs.2017. 10.042

Pulgar, V. M. (2018). Transcytosis to cross the blood brain barrier, new advancements and challenges. Front. Neurosci. 12:1019. doi: 10.3389/fnins.2018.01019

Qi, N., Cai, C., Zhang, W., Niu, Y., Yang, J., Wang, L., et al. (2014). Sustained delivery of cytarabine-loaded vesicular phospholipid gels for treatment of xenografted glioma. Int. J. Pharm. 472, 48-55. doi: 10.1016/j.ijpharm.2014.06.005

Qi, N., Tang, X., Lin, X., Gu, P., Cai, C., Xu, H., et al. (2012). Sterilization stability of vesicular phospholipid gels loaded with cytarabine for brain implant. Int. J. Pharm. 427, 234-241. doi: 10.1016/j.ijpharm.2012.02.008

Ramachandran, R., Junnuthula, V. R., Gowd, G. S., Ashokan, A., Thomas, J., Peethambaran, R., et al. (2017). Theranostic 3-Dimensional nano brainimplant for prolonged and localized treatment of recurrent glioma. Sci. Rep. 7:43271. doi: 10.1038/srep43271

Rauch, U. (2004). Extracellular matrix components associated with remodeling processes in brain. Cell. Mol. Life Sci. 61, 2031-2045. doi: 10.1007/s00018-004-4043-x

Read, T. A., Sorensen, D. R., Mahesparan, R., Enger, P. O., Timpl, R., Olsen, B. R., et al. (2001). Local endostatin treatment of gliomas administered by microencapsulated producer cells. Nat. Biotechnol. 19, 29-34. doi: 10.1038/83471 
Reinhard, J., Brösicke, N., Theocharidis, U., and Faissner, A. (2016). The extracellular matrix niche microenvironment of neural and cancer stem cells in the brain. Int. J. Biochem. Cell Biol. 81, 174-183. doi: 10.1016/j.biocel.2016.05.002

Rowland, M. J., Parkins, C. C., McAbee, J. H., Kolb, A. K., Hein, R., Loh, X. J., et al. (2018). An adherent tissue-inspired hydrogel delivery vehicle utilised in primary human glioma models. Biomaterials 179, 199-208. doi: 10.1016/j.biomaterials.2018.05.054

Saito, K., Yamasaki, K., Yokogami, K., Ivanova, A., Takeishi, G., Sato, Y., et al. (2017). Eosinophilic meningitis triggered by implanted Gliadel wafers: case report. J. Neurosurg. 126, 1783-1787. doi: 10.3171/2016.4.JNS152771

Sameshima, T., Nabeshima, K., Toole, B. P., Yokogami, K., Okada, Y., Goya, T., et al. (2000). Glioma cell extracellular matrix metalloproteinase inducer (EMMPRIN) (CD147) stimulates production of membrane-type matrix metalloproteinases and activated gelatinase $\mathrm{A}$ in co-cultures with brain-derived fibroblasts. Cancer Lett. 157, 177-184. doi: 10.1016/S0304-3835, 00485-7

Scanga, V. I., Goraltchouk, A., Nussaiba, N., Shoichet, M. S., and Morshead, C. M. (2010). Biomaterials for neural-tissue engineering-Chitosan supports the survival, migration, and differentiation of adult-derived neural stem and progenitor cells. Can. J. Chem. 88, 277-287. doi: 10.1139/v09-171

Seidenbecher, C. I., Richter, K., Rauch, U., Fässler, R., Garner, C. C., and Gundelfinger, E. D. (1995). Brevican, a chondroitin sulfate proteoglycan of rat brain, occurs as secreted and cell surface glycosylphosphatidylinositol-anchored isoforms. J. Biol. Chem. 270, 27206-27212. doi: 10.1074/jbc.270.45.27206

Senkov, O., Andjus, P., Radenovic, L., Soriano, E., and Dityatev, A. (2014). Neural ECM molecules in synaptic plasticity, learning, and memory. Prog. Brain Res. 214, 53-80. doi: 10.1016/B978-0-444-63486-3.00003-7

Sim, H., Hu, B., and Viapiano, M. S. (2009). Reduced expression of the hyaluronan and proteoglycan link proteins in malignant gliomas. J. Biol. Chem. 284, 26547-26556. doi: 10.1074/jbc.M109.013185

Später, T., Frueh, F. S., Metzger, W., Menger, M. D., and Laschke, M. W. (2018). In vivo biocompatibility, vascularization, and incorporation of Integra((R)) dermal regenerative template and flowable wound matrix. J. Biomed. Mater. Res. B Appl. Biomater. 106, 52-60. doi: 10.1002/jbm.b.33813

Srivastava, A., Yadav, T., Sharma, S., Nayak, A., Kumari, A., and Mishra, N. (2016). Polymers in drug delivery. J. Biosci. Med. 4, 69-84. doi: 10.4236/jbm.2016.41009

Stephan, M. T., and Irvine, D. J. (2011). Enhancing cell therapies from the outside in: cell surface engineering using synthetic nanomaterials. Nano Today 6, 309-325. doi: 10.1016/j.nantod.2011.04.001

Stoppel, W. L., Ghezzi, C. E., McNamara, S. L., Black, L. D. III, and Kaplan, D. L. (2015). Clinical applications of naturally derived biopolymerbased scaffolds for regenerative medicine. Ann. Biomed. Eng. 43, 657-680. doi: 10.1007/s10439-014-1206-2

Sturm, D., Pfister, S. M., and Jones, D. T. W. (2017). Pediatric gliomas: current concepts on diagnosis, biology, and clinical management. J. Clin. Oncol. 35, 2370-2377. doi: 10.1200/JCO.2017.73.0242

Sun, Y., Pollard, S., Conti, L., Toselli, M., Biella, G., Parkin, G., et al. (2008). Long-term tripotent differentiation capacity of human neural stem (NS) cells in adherent culture. Mol. Cell Neurosci. 38, 245-258. doi: 10.1016/j.mcn.2008.02.014

Suri, V., Das, P., Pathak, P., Jain, A., Sharma, M. C., Borkar, S. A., et al. (2009). Pediatric glioblastomas: a histopathological and molecular genetic study. Neurooncology 11, 274-280. doi: 10.1215/15228517-2008-092

Theocharis, A. D., Skandalis, S. S., Tzanakakis, G. N., and Karamanos, N. K. (2010). Proteoglycans in health and disease: novel roles for proteoglycans in malignancy and their pharmacological targeting. FEBS J. 277, 3904-3923. doi: $10.1111 / j .1742-4658.2010 .07800 . x$

Tian, W., Ying, X., Du, J., Guo, J., Men, Y., Zhang, Y., et al. (2010). Enhanced efficacy of functionalized epirubicin liposomes in treating brain glioma-bearing rats. Eur. J. Pharm. Sci. 41, 232-243. doi: 10.1016/j.ejps.2010.06.008

Trotter, J., Karram, K., and Nishiyama, A. (2010). NG2 cells: properties, progeny and origin. Brain Res. Rev. 63, 72-82. doi: 10.1016/j.brainresrev.2009.12.006

Tseng, Y. Y., Kao, Y. C., Liao, J. Y., Chen, W. A., and Liu, S. J. (2013). Biodegradable drug-eluting poly[lactic-co-glycol acid] nanofibers for the sustainable delivery of vancomycin to brain tissue: in vitro and in vivo studies. ACS Chem. Neurosci. 4, 1314-1321. doi: 10.1021/cn400108q
Turley, E. A., Hossain, M. Z., Sorokan, T., Jordan, L. M., and Nagy, J. I. (1994), Astrocyte and microglial motility in vitro is functionally dependent on the hyaluronan receptor RHAMM. Glia 12, 68-80. doi: 10.1002/glia.440120109

Tyler, B., Fowers, K. D., Li, K. W., Recinos, V. R., Caplan, J. M., Hdeib, A., et al. (2010). A thermal gel depot for local delivery of paclitaxel to treat experimental brain tumors in rats. J. Neurosurg. 113, 210-217. doi: 10.3171/2009.11.JNS08162

Ulrich, T. A., de Juan Pardo, E. M., and Kumar, S. (2009). The mechanical rigidity of the extracellular matrix regulates the structure, motility, and proliferation of glioma cells. Cancer Res. 69, 4167-4174. doi: 10.1158/0008-5472.CAN-08-4859

Varga, I., Hutóczki, G., Szemcsák, C. D., Zahuczky, G., Tóth, J., Adamecz, Z., et al. (2012). Brevican, neurocan, tenascin- $\mathrm{C}$ and versican are mainly responsible for the invasiveness of low-grade astrocytoma. Pathol. Oncol. Res. 18, 413-420. doi: 10.1007/s12253-011-9461-0

Veretennikoff, K., Walker, D., Biggs, V., and Robinson, G. (2017). Changes in cognition and decision making capacity following brain tumour resection: illustrated with two cases. Brain Sci. 7:E122. doi: 10.3390/brainsci7100122

Vinchon-Petit, S., Jarnet, D., Michalak, S., Lewis, A., Benoit, J. P., and Menei, P. (2010). Local implantation of doxorubicin drug eluting beads in rat glioma. Int J. Pharm. 402, 184-189. doi: 10.1016/j.ijpharm.2010.09.013

Wang, C., Tong, X., Jiang, X., and Yang, F. (2017). Effect of matrix metalloproteinase-mediated matrix degradation on glioblastoma cell behavior in 3D PEG-based hydrogels. J. Biomed. Mater. Res. A 105, 770-778. doi: $10.1002 / j b m . a .35947$

Wang, G., Wang, J. J., Tang, X. J., Du, L., and Li, F. (2016). In vitro and in vivo evaluation of functionalized chitosan-Pluronic micelles loaded with myricetin on glioblastoma cancer. Nanomedicine 12, 1263-1278. doi: 10.1016/j.nano.2016.02.004

Wang, Y., Chang, N., Zhang, T., Liu, H., Ma, W., Chu, Q., et al. (2010). Overexpression of human CAP10-like protein $46 \mathrm{KD}$ in T-acute lymphoblastic leukemia and acute myelogenous leukemia. Genet. Test. Mol. Biomarkers 14, 127-133. doi: 10.1089/gtmb.2009.0145

Watanabe, A., Mabuchi, T., Satoh, E., Furuya, K., Zhang, L., Maeda, S., et al. (2006). Expression of syndecans, a heparan sulfate proteoglycan, in malignant gliomas: participation of nuclear factor-kappaB in upregulation of syndecan-1 expression. J. Neurooncol. 77, 25-32. doi: 10.1007/s11060-005-9010-3

Wiranowska, M., Ladd, S., Smith, S. R., and Gottschall, P. E. (2006). CD44 adhesion molecule and neuro-glial proteoglycan NG2 as invasive markers of glioma. Brain Cell Biol. 35, 159-172. doi: 10.1007/s11068-007-9009-0

Wu, M. P., Tamada, J. A., Brem, H., and Langer, R. (1994). In vivo versus in vitro degradation of controlled release polymers for intracranial surgical therapy. J. Biomed. Mater. Res. 28, 387-395. doi: 10.1002/jbm.820280314

Xiao, H., Yan, L., Dempsey, E. M., Song, W., Qi, R., Li, W., et al. (2018). Recent progress in polymer-based platinum drug delivery systems. Prog. Polym. Sci. 87, 70-106. doi: 10.1016/j.progpolymsci.2018.07.004

Xie, H., Zhu, Y., Jiang, W., Zhou, Q., Yang, H., Gu, N., et al. (2011). Lactoferrinconjugated superparamagnetic iron oxide nanoparticles as a specific MRI contrast agent for detection of brain glioma in vivo. Biomaterials 32, 495-502. doi: 10.1016/j.biomaterials.2010.09.024

Xie, Y. T., Du, Y. Z., Yuan, H., and Hu, F. Q. (2012). Brain-targeting study of stearic acid-grafted chitosan micelle drug-delivery system. Int. J. Nanomed. 7, 3235-3244. doi: 10.2147/IJN.S32701

Xing, W. K., Shao, C., Qi, Z. Y., Yang, C., and Wang, Z. (2015). The role of Gliadel wafers in the treatment of newly diagnosed GBM: a meta-analysis. Drug Des. Devel. Ther. 9, 3341-3348. doi: 10.2147/DDDT.S85943

Xiong, A., Kundu, S., and Forsberg-Nilsson, K. (2014). Heparan sulfate in the regulation of neural differentiation and glioma development. FEBS J. 281, 4993-5008. doi: 10.1111/febs.13097

Yamaguchi, Y. (2000). Lecticans: organizers of the brain extracellular matrix. Cell Mol. Life Sci. 57, 276-289. doi: 10.1007/PL00000690

Yamahara, T., Numa, Y., Oishi, T., Kawaguchi, T., Seno, T., Asai, A., et al. (2010). Morphological and flow cytometric analysis of cell infiltration in glioblastoma: a comparison of autopsy brain and neuroimaging. Brain Tumor Pathol. 27, 81-87. doi: 10.1007/s10014-010-0275-7

Yang, G., Murashige, D. S., Humphrey, S. J., and James, D. E. (2015). A positive feedback loop between Akt and mTORC2 via SIN1 phosphorylation. Cell Rep. 12, 937-943. doi: 10.1016/j.celrep.2015.07.016 
Yang, J., Li, Y., Zhang, T., and Zhang, X. (2016). Development of bioactive materials for glioblastoma therapy. Bioact Mater. 1, 29-38. doi: 10.1016/j.bioactmat.2016.03.003

Yu, C., Griffiths, L. R., and Haupt, L. M. (2017). Exploiting heparan sulfate proteoglycans in human neurogenesis-controlling lineage specification and fate. Front Integr. Neurosci. 11:28. doi: 10.3389/fnint.2017. 00028

Yu, Q., and Stamenkovic, I. (1999). Localization of matrix metalloproteinase 9 to the cell surface provides a mechanism for CD44-mediated tumor invasion. Genes Dev. 13, 35-48. doi: 10.1101/gad.13. 1.35

Yu, Y., Xu, Q., He, S., Xiong, H., Zhang, Q., Xu, W., et al. (2019). Recent advances in delivery of photosensitive metal-based drugs. Coord. Chem. Rev. 387, 154-179. doi: 10.1016/j.ccr.2019.01.020

Zamecnik, J. (2005). The extracellular space and matrix of gliomas. Acta Neuropathol. 110, 435-442. doi: 10.1007/s00401-0051078-5
Zhao, M., Danhier, F., Bastiancich, C., Joudiou, N., Ganipineni, L. P. Tsakiris, N., et al. (2018). Post-resection treatment of glioblastoma with an injectable nanomedicine-loaded photopolymerizable hydrogel induces longterm survival. Int. J. Pharm. 548, 522-529. doi: 10.1016/j.ijpharm.2018. 07.033

Conflict of Interest: The authors declare that the research was conducted in the absence of any commercial or financial relationships that could be construed as a potential conflict of interest.

Copyright (c) 2019 Belousov, Titov, Shved, Garbuz, Malykin, Gulaia, Kagansky and Kumeiko. This is an open-access article distributed under the terms of the Creative Commons Attribution License (CC BY). The use, distribution or reproduction in other forums is permitted, provided the original author(s) and the copyright owner(s) are credited and that the original publication in this journal is cited, in accordance with accepted academic practice. No use, distribution or reproduction is permitted which does not comply with these terms. 